\title{
Sensitivity of Model-Generated Daytime Surface Heat Fluxes over Snow to Land-Cover Changes
}

\author{
John E. Strack and Roger A. Pielke Sr. \\ Department of Atmospheric Science, Colorado State University, Fort Collins, Colorado \\ JIMMY ADEGOKE \\ Cooperative Institute for Research in the Atmosphere, Colorado State University, Fort Collins, Colorado
}

(Manuscript received 18 October 2001, in final form 14 May 2002)

\begin{abstract}
Snow cover can significantly suppress daytime temperatures by increasing the surface albedo and limiting the surface temperature to $0^{\circ} \mathrm{C}$. The strength of this effect is dependent upon how well the snow can cover, or mask, the underlying surface. In regions where tall vegetation protrudes through a shallow layer of snow, the temperature-reducing effects of the snow will be suppressed since the protruding vegetation will absorb solar radiation and emit an upward turbulent heat flux. This means that an atmospheric model must have a reasonable representation of the land cover, as well as be able to correctly calculate snow depth, if an accurate simulation of surface heat fluxes, air temperatures, and boundary layer structure is to be made. If too much vegetation protrudes through the snow, then the surface sensible heat flux will be too large and the air temperatures will be too high.

In this study four simulations are run with the Regional Atmospheric Modeling System (RAMS 4.30) for a snow event that occurred in 1988 over the Texas Panhandle. The first simulation, called the control, is run with the most realistic version of the current land cover and the results verified against both ground stations and aircraft data. Simulations 2 and 3 use the default methods of specifying land cover in RAMS 4.29 and RAMS 4.30 , respectively. The significance of these variations in land-cover definition is then examined by comparing with the control run. Finally, the last simulation is run with the land cover defined as all short grass, the natural cover for the region. The results of this study indicate that variations in the land-cover specification can lead to differences in sensible heat flux over snow as large as $80 \mathrm{~W} \mathrm{~m}^{-2}$. These differences in sensible heat flux can then lead to differences in daytime temperatures of as much as $6^{\circ} \mathrm{C}$. Also, the height of the afternoon boundary layer can vary by as much as $200-300 \mathrm{~m}$.

In addition, the results suggest that daytime temperatures are cooler over snow in the regions where short grass has been converted to cropland, while they appear to be warmer over regions where shrubs have increased.
\end{abstract}

\section{Introduction}

Several studies have shown that snow can significantly reduce daytime temperatures by as much as $10^{\circ} \mathrm{C}$ on timescales of days to months (Namias 1985; Cohen and Rind 1991; Baker et al. 1992; Leathers and Robinson 1993; Ellis and Leathers 1998). Snow cover reduces daytime temperatures by increasing the net surface albedo and reducing the maximum attainable surface temperature. First of all, the higher surface albedo reduces the amount of incoming solar radiation that can be absorbed, meaning less energy will be available to heat the surface and nearby air. Second, the temperature of the snow is limited to $0^{\circ} \mathrm{C}$ or less. Once the snow

Corresponding author address: John E. Strack, Department of Atmospheric Science, Colorado State University, 1371 Campus Delivery, Fort Collins, CO 80523.

E-mail: jstrack@atmos.colostate.edu temperature reaches $0^{\circ} \mathrm{C}$ the remaining energy can only be used for melting. These two effects combine to produce a surface that is significantly cooler than its snowfree counterpart under the same ambient conditions.

The strength of these cooling effects is obviously dependent upon the extent to which the snow is able to cover, or mask, the land surface. When tall vegetation, such as trees or shrubs, protrude through a shallow snow cover the albedo increasing effect of the snow is reduced; see Fig. 1. Furthermore, the protruding vegetation is capable of warming to temperatures greater than the $0^{\circ} \mathrm{C}$ limit of snow, allowing for a greater surface sensible heat flux. Liston (1995) used a numerical model to show that the energy available for melting increases by as much as $30 \%$ as the area of exposed vegetation in the upwind direction increases. In contrast, the same shallow snow cover may be able to completely bury short vegetation, such as grass or crop stubble, enabling the full temperature-reducing effects of the snow to be 


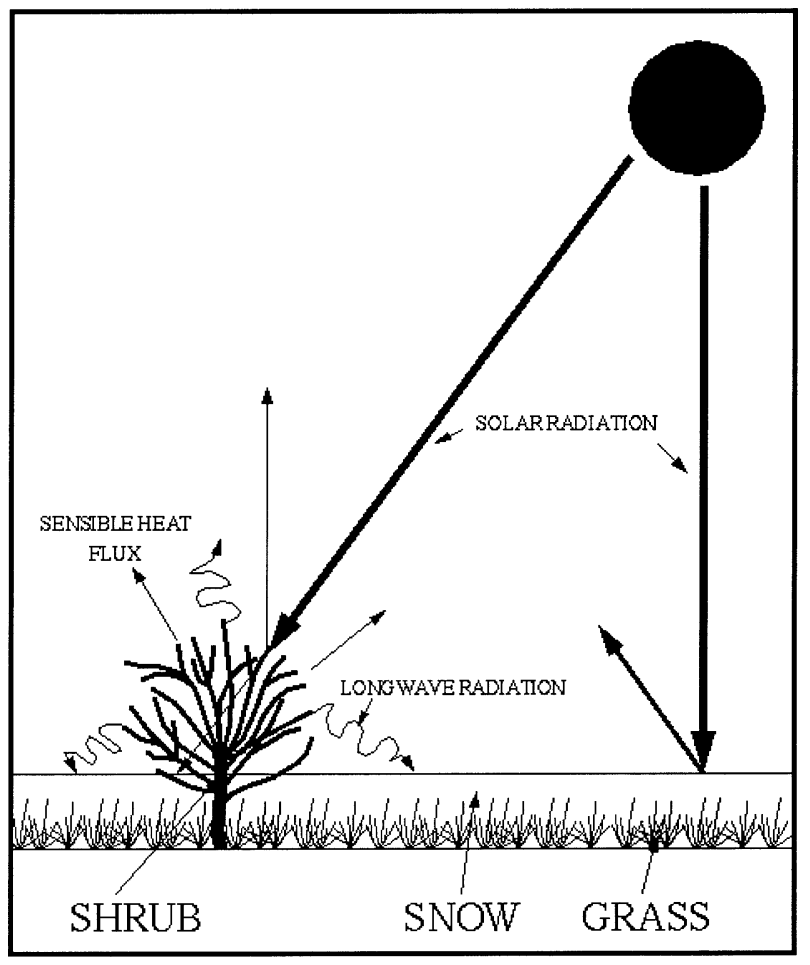

FIG. 1. Schematic showing the key energy exchange mechanisms over a snow cover interspersed with protruding shrubs.

realized. In the case of the study by Baker et al. (1992) the mean reduction in daily maximum temperature was $8.4^{\circ} \mathrm{C}$ when the surface was completely masked and $6.5^{\circ} \mathrm{C}$ when the surface was partially masked by snow.

Some modeling studies have also looked at the influence of protruding vegetation on temperatures and heat fluxes over snow. The sensitivity of surface heat fluxes and low-level air temperature to masking of the land cover by snow has been examined for the boreal forests of the Northern Hemisphere by Thomas and Rowntree (1992) and Viterbo and Betts (1999). In addition, Greene et al. (1999) illustrated the importance of the albedo reduction by forests in the Rocky Mountains. Thomas and Rowntree (1992) represented the removal of the boreal forests as an increase in the maximum winter and spring albedo over these regions in the United Kingdom's Meteorological Office (Met Office) general circulation model. The albedo of the boreal forest regions in the winter and spring is generally much lower than that of snow since the dark trees easily protrude through the snow pack. The removal of these forests would lead to a significant increase in the surface albedo of the region. In the Thomas and Rowntree (1992) study the increase in albedo due to forest removal led to a reduction in surface sensible heat fluxes, air temperatures, and precipitation during the spring. Viterbo and Betts (1999) showed that a reduction in the boreal forest deep snow albedo in the European Centre for Medium-Range Weather Forecasts (ECMWF) model significantly reduced the model's cold low-level temperature bias present in the boreal forest region during the spring. The ECMWF model had been neglecting the reduction in albedo due to the protruding forest and assigned a value for the surface albedo that was too high, leading to the cold bias in low-level temperatures. Finally, Greene et al. (1999) showed with the climate version of the Regional Atmospheric Modeling System (ClimRAMS) model that surface sensible heat fluxes and low-level air temperatures were reduced during late winter and early spring when forest areas were replaced with grassland in the Rocky Mountains.

Clearly the ability of an atmospheric model to correctly simulate daytime temperatures over snow is linked to the accuracy of the land-cover definition. If the land cover in a model is defined to be 1-m tall shrubs when, in fact, $5-\mathrm{cm}$ crop stubble is present, then one would expect the model to overpredict the surface heat flux over a $15-\mathrm{cm}$ deep snow cover. The overpredicted surface heat flux would in turn lead to higher nearsurface air temperatures and a deeper afternoon boundary layer.

This study seeks to illustrate the sensitivity of modelsimulated daytime temperatures over snow to the underlying land cover. The Colorado State University Regional Atmospheric Modeling System (CSU-RAMS; Pielke et al. 1992) version 4.30 is used to run four 12h-long simulations centered in the Texas Panhandle. The first three will each use a different method of specifying the present-day land cover. The first simulation, which is considered the control, uses the $30-\mathrm{m}$ resolution Landsat Thematic Mapper (TM)-derived National Land Cover Data (NLCD) to define the present-day land cover (Vogelmann et al. 1998). Simulations 2 and 3 utilize the 1-km resolution Advanced Very High-Resolution Radiometer (AVHRR)-derived Olson Global Ecosystem (OGE) land-cover data to define the present-day land cover (Olson 1994a,b). Finally, in simulation 4 the land cover will be defined as all short grass, the predominant presettlement vegetation in the southern Great Plains. The evolution of sensible and latent heat fluxes, nearsurface air temperature, snow depth, and boundary layer structure as simulated by the model is then examined for each of the land-cover definitions. In contrast to the modeling studies mentioned above, this experiment focuses on the effects of protruding vegetation with relatively small stature, such as shrubs, on the boundary layer. In addition, this study examines these effects in a midlatitude and relatively low-altitude region. The research is also different since it explores the significance of not only changes in land cover in a region, but also the sensitivity to different methods of specifying the current land cover. The overall goal here is to highlight the necessity of properly representing the land cover in numerical weather prediction and climate models and how slight variations between different land-cover datasets can lead to significant differences in model results. The study also provides further evidence of how chang- 
TABLE 1. List of the four simulations.

\begin{tabular}{llcc}
\hline \hline Simulation & Control run & Simulation 2 & Simulation 3 \\
\hline Land cover & Landsat TM & $\begin{array}{c}\text { AVHRR: shrub-grass mix de- } \\
\text { fined as all shrub }\end{array}$ & $\begin{array}{c}\text { AVHRR: shrub-grass mix de- } \\
\text { fined as all short grass }\end{array}$ \\
\hline
\end{tabular}

es in land cover over time can lead to changes in lowlevel air temperatures, and hence the need for treating the land surface as a dynamic component of any climate system model. Finally, the results of this work will further show the need for considering land-cover changes when examining long-term temperature records from surface stations for trends.

Section 2 explains the design of the experiment and qualitatively describes the Land Ecosystem-Atmosphere Feedback model version 2 (LEAF-2) land-surface parameterization used by RAMS. An extensive discussion of the control run configuration is given in section 3, followed by a comparison of the control run results with observations and a discussion of the other simulations in section 4. Finally, section 5 contains a summary and recommendations for future work.

\section{Experimental design}

\section{a. Experiment methodology}

RAMS 4.30 with LEAF-2 is used to simulate daytime temperatures over a 5-30-cm deep cover of melting snow in the Texas Panhandle on 18 March 1988. On this day a large high pressure system was located over the Rocky Mountains to the west producing fair skies, subsidence, and light northwesterly surface flow. This particular event was chosen because of its location in a region where significant land-use change has occurred, as well as the availability of heat flux and albedo measurements from the Snow Shading Boundary Layer Interaction Measurement Program (SSBLIM) described in Cramer (1988). The region is also ideal because a large fraction of it is defined as a mixed shrub and grass category in the OGE AVHRR-derived dataset, which is the standard land-cover set for LEAF-2. This category presents a problem since there is no such corresponding mixed class in the Biosphere Atmosphere Transfer Scheme (BATS; Dickinson et al. 1986) with which LEAF-2 cross references the Olson classes. The mixed class is either defined as all shrubs, as was the case in RAMS 4.29, or all grass, as in RAMS 4.30. As is shown later this has significant consequences for daytime temperatures over snow. The first step is to run a simulation with the best land-cover representation available and compare the results to the available observations. This simulation, which we will call the control, will be the baseline to which we compare the results of all subsequent simulations. We consider the $30-\mathrm{m}$ resolution Landsat TM-derived land cover to be the best for the Texas Panhandle since it distinguishes between the grass and shrubs, allowing for separate fractions for each to be defined in LEAF-2, and appears to give a better fraction of cropland. After demonstrating with the control run that the model can reasonably reproduce available observations, we make the assumption that the results from subsequent simulations with land-cover modifications are a reasonable representation of what would actually occur if such land-cover changes occurred. The second simulation will be run using the 1-km AVHRRderived land cover with the grass and shrub mixture, described above, classified as all shrubs in LEAF-2; and the third simulation will be run with this class defined as all short grass. Finally, the fourth simulation will be run with the entire land cover defined simply as all short grass, a situation that represents the presettlement, or natural state, of the land. The four simulations are listed in Table 1 for reference.

We expect that representing the shrub-grass mixture as all shrubs will lead to higher daytime temperatures. The tall shrubs protrude through the snow and thus are warmed by the sun. As a result upward turbulent sensible heat flux occurs. Since the fraction of the shrubs will be much larger in this case, the afternoon air temperatures will be correspondingly higher. The opposite situation is expected for simulation 3 where the shrubgrass mix will be treated as all short grass. In this case the fraction of shrubs will be smaller leading to a reduction in afternoon temperatures. From simulation 4 we expect to find that an increase in the shrub population in this region since presettlement conditions may produce higher daytime temperatures over snow. Also, cooler temperatures are expected over the crop stubble areas since the stubble is generally shorter than the natural grass.

\section{b. $L E A F-2$}

LEAF-2 is the land-surface parameterization used by RAMS 4.30. Much of the following description, which is included for completeness, is taken from Walko et al. (2000). LEAF-2 consists of the soil, snow or temporary surface water, vegetation, and canopy air. Each grid cell in RAMS is broken down into a permanent surface water patch and an additional user-defined number of landcover-type patches. The permanent surface water patch represents the fraction of the grid cell that is occupied by rivers, lakes, or ocean while the other patches represent the fractions of the most dominant land-cover types. LEAF-2 is run separately for each of the patches and the influence of each patch on the lowest atmospheric level in RAMS is weighted according to its fractional area. There is no direct communication between 
the patches; however, they influence each other indirectly through their effects on the lowest atmospheric level in RAMS. This fractional breakdown of the land surface allows the land cover, which often has fine spatial structure, to be represented at relatively higher resolution than the more computationally expensive atmospheric grid. A qualitative description of each of the components of LEAF-2 that are most relevant to this study is given in the sections that follow. A comprehensive listing of the equations in LEAF- 2 can be found in Lee (1992) and in appendix D of Pielke (2002).

\section{1) SNOW}

Snow is considered to be the frozen part of the temporary surface water component in LEAF-2. Multiple snow layers are allowed. Equation (1), shown below, defines the snow internal energy in joules per kilogram:

$$
Q_{s}=f_{i} C_{i} T_{s}+f_{l}\left(C_{l} T_{s}+L_{\mathrm{il}}\right),
$$

where $T_{s}$ is the snow temperature in degrees Celsius $f_{i}$ is the ice fraction, $f_{l}$ is the liquid fraction, $C_{i}$ is the specific heat of ice, $C_{l}$ the specific heat of water, and $L_{\mathrm{il}}$ the latent heat of fusion of water. This gives the internal energy relative to a reference state of all ice at $0^{\circ} \mathrm{C}$, at which point $Q_{s}$ is 0 . At each time step, $Q_{s}$ in the topmost snow layer is updated by the net radiation, conduction of heat from the layer below, energy carried by the net flux divergence of liquid water percolation, and latent heat flux from evaporation and sublimation to canopy air. In intermediate layers $Q_{s}$ is updated from the absorption of transmitted solar radiation, conduction between adjacent layers, and by energy carried by the net flux divergence of percolating liquid water. Finally, for the bottom-most snow layer, $Q_{s}$ is updated from absorbed transmitted solar radiation, energy carried by the net flux divergence of percolating liquid water, and conduction of heat from both the soil surface and the next snow layer above. The new internal energy is used to calculate the snow temperature and liquid water fraction.

By default in LEAF-2 the snow albedo is assigned a maximum value of 0.5 when in the form of all ice. The albedo decreases linearly to the value for wet soil (0.14) as the liquid fraction increases to 1 . For this study the same linear decrease to 0.14 is used but the maximum albedo has been increased to 0.6. Ample documentation exists (Hartmann 1994; Sellers 1965) supporting much higher values for the snow albedo; however, the lower value of 0.6 was chosen because the model grid is too coarse to represent the high degree of snow depth variability present across melting snowpacks. When snow is present in a land-cover patch, it is assumed to have uniform depth across the entire patch. In reality, there will be variability in the snow depth across a region as large as the patches used in this simulation. This means that the fraction of exposed vegetation is likely to be underestimated, and any bare ground that may be present is not accounted for at all. By lowering the snow albedo, an attempt is made to make up for this difference. The value of 0.6 gives net surface albedos that agree fairly well with those observed in the SSBLIM study. In reality, the albedo of snow also has a spectral dependence where the albedo decreases with longer wavelengths. However, in LEAF-2 the albedo is held constant across all wavelengths for solar radiation. The longwave emissivity of the snow is assumed to be unity.

In the current implementation of LEAF-2 the snow depth is updated each time step by the amount of snow reaching the ground and snowmelt. The depth also decreases each time due to a prescribed compression rate as shown in the following equation:

$$
z_{s}=z_{s}\left(1-\frac{\Delta t}{1 \times 10^{5}}\right),
$$

where $\Delta t$ is the time step in seconds, and $z_{s}$ is snow depth in meters.

The amount of snowmelt is calculated in terms of mass per unit area, and the depth loss is computed as the depth this mass would fill if in the form of liquid water. For this study the snow depth is simply diagnosed from the ice and liquid water fractions with the density of the ice fraction remaining constant with time. At each time step, the depths of liquid water and ice are computed and summed to get the total snow depth. The density of the ice fraction of the snow is assumed to remain constant at its initial value. The assumption of a constant value for the ice fraction density is not too bad for this situation since the duration of the simulation is so short and the snow is relatively shallow. Internal compression from the weight of the snow itself will not be very large in this case. This alternative method for determining snow depth evolution was utilized for this study because the standard method does not allow for significant differences in snow depth due to differences in the rate of conversion of ice to liquid. Most of the depth change comes from the prescribed compression given by Eq. (2), which has no dependence upon conversion of ice to liquid.

\section{2) Vegetation}

In RAMS 4.30, LEAF-2 cross references all vegetation types either to 1 of the 18 BATS categories or, in a few cases, to a wooded grassland or urban category for which physical parameters have been defined. The vegetation physical parameters used by LEAF-2 are albedo, leaf area index (LAI), vegetation fraction, emissivity, roughness length, displacement height, and root depth. The LAI and vegetation fraction are allowed to vary on a prescribed seasonal basis. Vegetation fraction represents the fraction of the ground surface that is covered by vegetation. The rest of the surface is considered to be bare soil. 


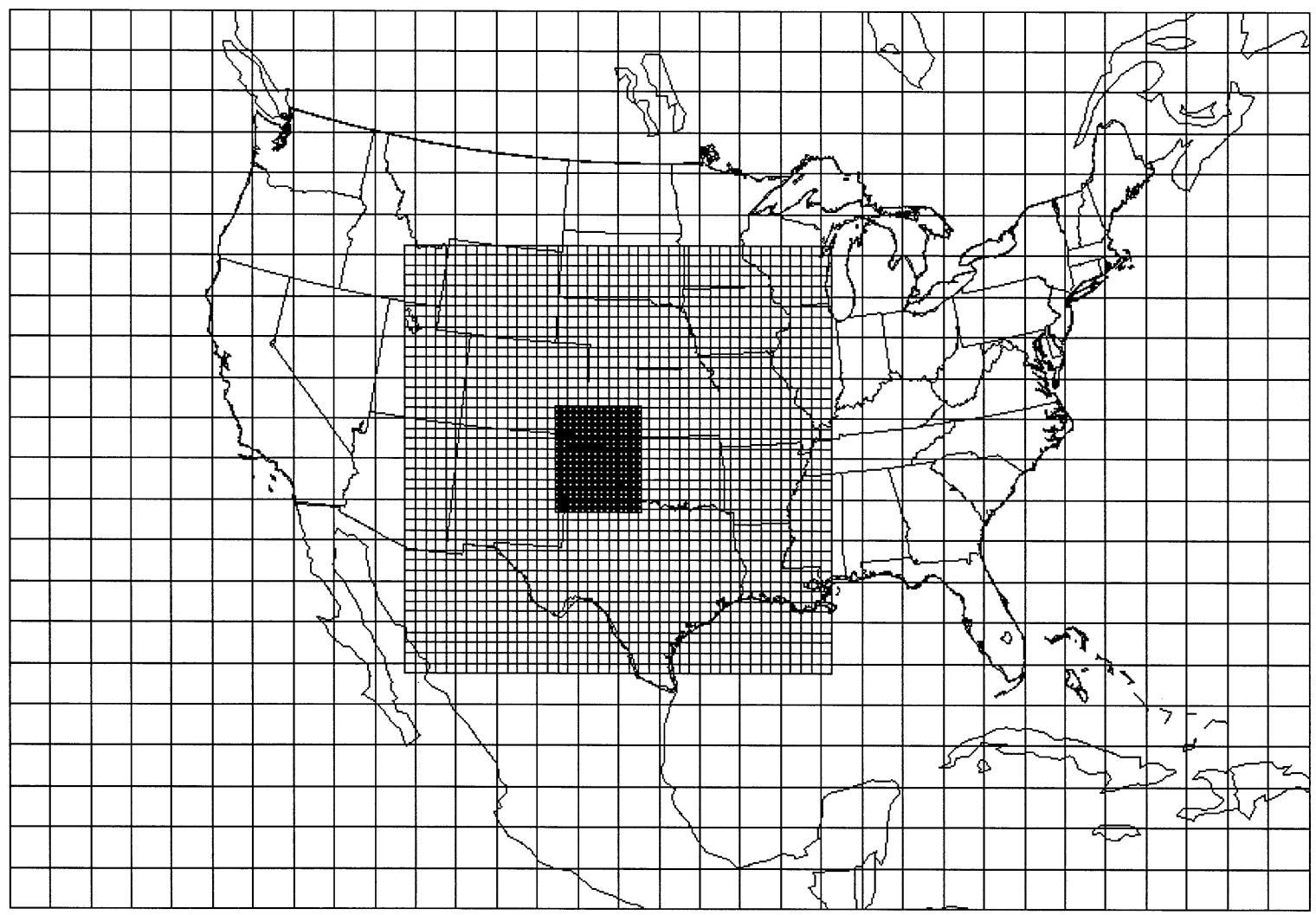

FIG. 2. Atmospheric grids used for all four of the simulations.

The vegetation temperature is calculated from the amount of energy exchanged between the net radiation, turbulent sensible heat flux, latent heat flux from evaporation of intercepted precipitation, latent heat flux from the process of transpiration, and energy carried by intercepted precipitation. The net radiation is the sum of absorbed solar radiation and longwave radiation from the atmosphere and the ground or snow surface.

The amount of solar and longwave radiation absorbed by the vegetation is proportional to the vegetation fraction. Similarly, the sensible heat flux emitted by the vegetation is proportional to the LAI. When snow is present, the vegetation fraction and LAI are assumed to decrease linearly toward 0 as snow depth approaches the height of the vegetation. As mentioned earlier, the model does not account for subgrid-scale snow depth variability. This means simultaneous emission of sensible and longwave heat fluxes from both bare ground and protruding vegetation in a patch is not possible since snow depth is constant. By lowering the snow albedo, an attempt is made to reduce the effects of this deficiency on snowmelt rate and the net absorption of solar radiation by the patch.

LEAF-2 in its present state cannot accurately produce sensible heat fluxes from vegetation that is completely bare of leaves, since it is based on LAI. In order to get around this, the sensible heat flux from the shrubs is modeled as being equal to the net radiation absorbed by the branches as in Otterman et al. (1993). This assumes that the heat capacity of the shrubs is very small and that there is no cooling due to latent heat of evaporation. Cooling of the shrubs by latent heat of evaporation will be negligible in this situation since they are dormant and dry.

\section{3) CANOPY AIR}

The canopy air is considered to be the air in immediate contact with the vegetation and surface. The canopy air temperature is calculated from turbulent sensible heat flux from the vegetation and ground or snow, and the sensible heat flux to the lowest atmospheric model level. The moisture content of the canopy air is calculated from the rate of moisture exchange between the ground or snow, intercepted precipitation on vegetation, transpiration, and the lowest atmospheric model level.

\section{Model configuration}

\section{a. Atmospheric initialization}

Three nested grids, as shown in Fig. 2, are used in this study. The outermost coarse grid covers most of North America and has horizontal grid intervals of 200 $\mathrm{km}$. The second grid covers a large part of the central United States and has horizontal intervals of $50 \mathrm{~km}$, 
while the innermost grid is centered on the Texas Panhandle with horizontal grid intervals of $10 \mathrm{~km}$. On the two outer grids, vertical grid intervals range from $30 \mathrm{~m}$ near the surface to $1000 \mathrm{~m}$ above the 5-km level. Vertical grid intervals on the fine grid range from $10 \mathrm{~m}$ in the first $120 \mathrm{~m}$ to $1000 \mathrm{~m}$ above the $5-\mathrm{km}$ level. The two coarse grids have a total of 47 levels reaching an altitude of about $18 \mathrm{~km}$. The fine grid has 59 levels, which also extend to about $18 \mathrm{~km}$.

The model is initialized at 1200 UTC 18 March 1988 with the National Centers for Environmental Prediction-National Center for Atmospheric Research (NCEP-NCEP) reanalysis (Kalnay et al. 1996) along with available surface and rawinsonde observations. The simulation is run for $12 \mathrm{~h}$. The Smagorinsky (Smagorinsky et al. 1965) and Mellor-Yamada (Mellor and Yamada 1982) turbulence schemes are used for horizontal and vertical diffusion, respectively. Both shortwave and longwave radiation are parameterized using the Chen and Cotton (Chen and Cotton 1983) routine. The boundaries of the outermost grid are nudged toward the NCEP-NCAR reanalysis at the halfway point of the simulation.

\section{b. Land-cover specification}

For all simulations, the 1-km AVHRR-derived OGE land-cover data are used to specify the land cover in the regions outside of the fine grid. In the control simulation, a $1-\mathrm{km}$ resolution version of the $30-\mathrm{m}$ Landsat TM-derived NLCD is used to define the land cover in the region of the fine domain. The $1-\mathrm{km}$ data contain the aggregated percentage of the area occupied by each of the 21 NLCD land-cover types in the original 30-m data. Some spatial resolution is lost by using the $1-\mathrm{km}$ land-cover data, but this does not adversely affect our simulations since the horizontal grid increment of the finest RAMS grid is $10 \mathrm{~km}$. Moreover, the crucial information on the fractional area of each land-cover type required for individual RAMS grid cells can be directly computed from the $1-\mathrm{km}$ data.

There is a considerable amount of cropland in the Texas Panhandle. The primary crops grown in this region are grain sorghum, winter wheat, cotton, and corn. During mid-March, sorghum, corn, and cotton fields are typically stubble while the winter wheat is growing. The Landsat data defines the cropland as either row crops or small grains. Corn and cotton are the two dominant row crops in the region. The row crop fractions are considered to be stubble in the winter.

Treating the small grain category is more tricky since part of this is winter wheat, which is green, in contrast to sorghum, the other small grain in the area, which is a summer crop and thus stubble in March. A typical crop rotation used in this region is the wheat-sorghumfallow rotation described in Jones and Popham (1997). Taking this into consideration, a third of the small grain area is estimated to be winter wheat and the other two-
TABLE 2. The key physical parameters for the vegetation types most prevalent in the study area.

\begin{tabular}{lcccc}
\hline \hline & LAI & $\begin{array}{c}\text { Vegetation } \\
\text { fraction }\end{array}$ & $\begin{array}{c}\text { Canopy height } \\
(\mathrm{m})\end{array}$ & Albedo \\
\hline Short grass & 1.3 & 0.74 & 0.20 & 0.25 \\
Shrubs & 0.1 & 0.50 & 1.60 & 0.15 \\
Stubble & 1.0 & 0.60 & 0.05 & 0.25 \\
Winter wheat & 1.3 & 0.74 & 0.10 & 0.20 \\
\hline
\end{tabular}

thirds is stubble. Crop stubble in this region is typically flat from tillage practices and weathering by mid-March (R. L. Baumhardt USDA-RDA, 2001, personal communication). Two new vegetation classes were created in LEAF-2 to represent crop stubble and winter wheat. In the case of the stubble the albedo is set to 0.25 , a typical value for dry vegetation (Hartmann 1994), the LAI is set to 1 , and the vegetation fraction and canopy height are set to 0.6 and $0.05 \mathrm{~m}$, respectively (R. L. Baumhardt 2001, personal communication). The remaining parameters were left the same as those for the crop/mixed farming class in BATS. The winter wheat category was derived from the BATS short grass class, with the exceptions that the albedo was decreased to 0.2 , a typical value for green vegetation (Hartmann 1994), the LAI was reduced from the BATS value to 1.3 (as estimated for short grass; W. Parton Natural Resource Ecology Laboratory, 2001, personal communication), and the canopy height was reduced to $0.1 \mathrm{~m}$ (R. L. Baumhardt 2001, personal communication).

The dominant noncrop land-cover types in the Texas Panhandle are short grass and shrubs. The most common short grass types are blue grama and buffalograss, while the dominant shrub is honey mesquite (Scifres 1980). Typical heights for buffalograss range from 0.05 to 0.25 $\mathrm{m}$ while those for blue grama are $0.2-0.7 \mathrm{~m}$ (Hatch and Pluhar 1993). With this in mind an average height of $0.2 \mathrm{~m}$ is given to the short grass category. The LAI is assigned a typical summer value of 1.3 (W. Parton 2001, personal communication). Here we have assumed that most of the grass stems and leaves remain through the winter even though they are dormant. Albedo is set to 0.25, a typical value for dry vegetation (Hartmann 1994). The other parameters for short grass are left the same as the defaults in LEAF-2. Honey mesquite shrubs are deciduous and have typical heights of 1-4 m (Hatch and Pluhar 1993). The LAI of the shrubs is set to 0.1 since most of the leaves will be off in mid-March, and the vegetation fraction is reduced to 0.5 (W. Parton 2001, personal communication). The albedo has been set to 0.15 , a reduction from the default in the shrub category of 0.20 , in response to the lower LAI value used here. The rest of the shrub parameters are left the same as the defaults in LEAF-2. Table 2 summarizes the key physical parameters for the vegetation types that are most prevalent in the study area. The reader should realize that there is considerable uncertainty in these parameters, and their variation could lead to changes in 


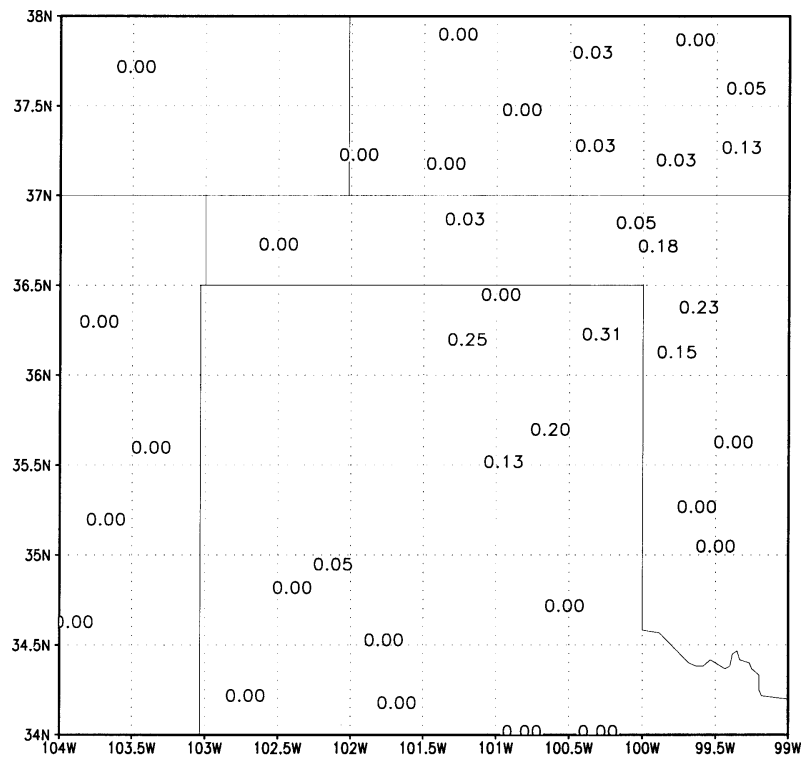

FIG. 3. USSOD stations used for initializing the snow depth. Values represent the observed snow depth $(\mathrm{m})$ on or about 1200 UTC 18 Mar 1988.

the energy fluxes from the vegetation that are as large as those induced by changing the vegetation type itself.

\section{c. Snow-cover initialization}

Snow cover is initialized using a combination of U.S. Summary of the Day (USSOD) observations and visible satellite imagery. The first step was to select all USSOD stations with observation times within $2 \mathrm{~h}$ of the model start time of 1200 UTC. Those stations in the region of interest are shown in Fig. 3. The snow depths from these stations were then interpolated on to the three RAMS grids. The area distribution of the snow over the region of interest on the fine grid was further refined with the aid of visible satellite imagery; see Fig. 4. In particular, the fork in the snow field shown in the satellite image was not reproduced in the interpolation due to sparseness of data, and so it was added manually.

The initial density of the snow was set to $100 \mathrm{~kg} \mathrm{~m}^{-3}$, a value determined from a liquid water measurement at Amarillo, Texas, $6 \mathrm{~h}$ before model start time of 1200 UTC. The air temperature across the snow region was well below freezing, between $-11^{\circ} \mathrm{C}$ and $-5^{\circ} \mathrm{C}$, and so the snow was assumed to be all ice at model initialization time. Since skies were clear and winds relatively light in the area during the nighttime hours leading up to the model start time, which is about an hour before local sunrise, the snow temperature is assigned a temperature equal to $3 \mathrm{~K}$ less than the lowest model-level $(\sim 5 \mathrm{~m})$ air temperature. Under such conditions one would expect significant radiational cooling to lower the temperature of the surface to below that of the low-level air. The internal energy of the snow is then initialized from Eq. (1).

\section{d. Soil initialization}

There are 10 soil layers extending down to 1-m depth. The soil layer thickness ranges from $5 \mathrm{~cm}$ near the surface to $20 \mathrm{~cm}$ at the deepest level. Soil type is defined as sandy clay loam in all grid cells and at all levels. The methods for assigning initial values of temperature and moisture to the soil are described below.

\section{1) SOIL TEMPERATURE}

Unfortunately there are no observations of soil temperature for the Texas Panhandle on this date, so the temperatures are estimated from the initial screen-height air temperature and snow depth. In order to initialize the soil temperature, two cases are considered: snow covered and snow free. We did this to reflect the insulating effects of snow on the underlying soil. The approach is to first define a snow-free profile based on average March air and soil temperature differences measured at the Bushland, Texas, U.S. Department of Agriculture (USDA) Soil Climate Analysis Network (SCAN) site. This profile is then warmed slightly according to snow depth based on measurements taken in the former Soviet Union during the 1940s and listed in Shul'gin (1965). A further correction is made to account for the latent heat of fusion given off when the moisture in the soil freezes. This procedure assigns a temperature of $0^{\circ} \mathrm{C}$, with the moisture partly in the form of ice, to the top soil layer over most of the snow-free areas of the fine grid. At the present time, the existence of supercooled soil moisture is not accounted for in LEAF2. The inclusion of supercooled soil moisture would be an improvement. Further details concerning the soil temperature initialization can be found in Strack (2001).

\section{2) Soll MOISTURE}

The soil moisture is initialized with output from a single-layer soil model described in Huang et al. (1996). The model uses observed monthly temperature and precipitation data for the 344 U.S. climate divisions to estimate runoff, evaporation, and soil moisture. Data is available from the Climate Prediction Center for the last day of each month from the year 1931 to the present. The values for 18 March 1988 are linearly interpolated from the output for 29 February and 31 March 1988.

\section{Results and discussion}

\section{a. Station observations}

In this section the results from the simulations are compared with the observations taken at Amarillo, Texas; Dodge City, Kansas; Borger, Texas; Wellington, Texas; and Sublette, Kansas. Since the results for simulation 4 are very similar to those for simulation 3 in all cases they are not plotted or discussed explicitly. Observed screen-height air temperatures and potential temperature 


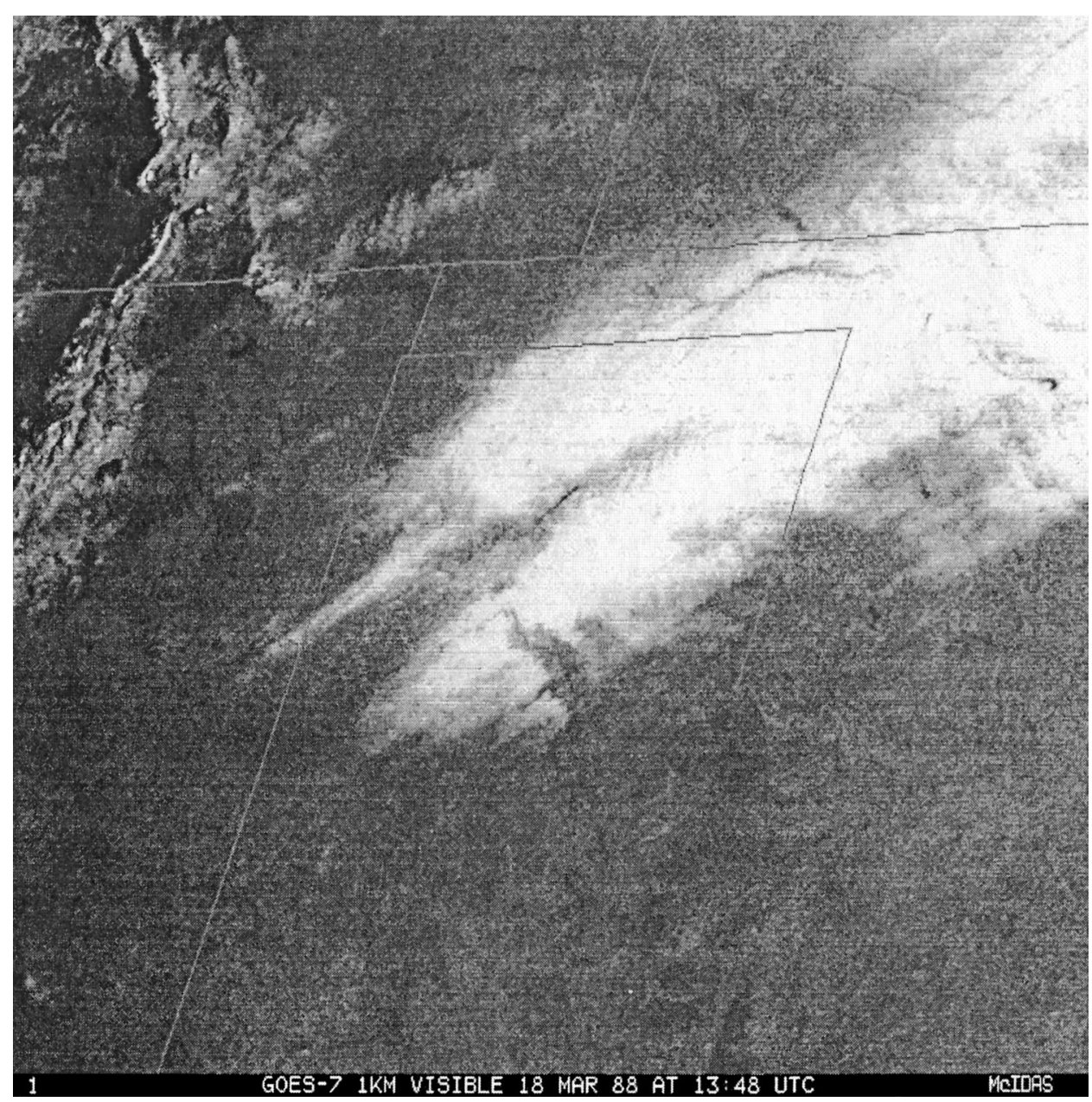

FIG. 4. Snow cover as shown by $1-\mathrm{km}$ resolution visible satellite imagery at 1348 UTC 18 Mar 1988.

profiles at Amarillo, Texas, and Dodge City, Kansas (see Fig. 5), are compared with the model output. Amarillo had $5 \mathrm{~cm}$ of snow on the ground at initialization time and Dodge City was snow free during the entire simulation. The comparisons with these two sites will give some insight into how well the model can simulate air temperature and boundary layer evolution over both snow-covered and snow-free ground. The correlation coefficients between the observations and the various simulations are shown in Table 3.

\section{1) AmARILlo}

The potential temperature profiles for 1200 UTC 18 March 1988 (model start time) and 0000 UTC 19 March 1988 at Amarillo, Texas, are shown in Fig. 6. The initial profiles in the model are the result of interpolation of the reanalysis and upper-air observations to the RAMS grid. The model profiles that are compared with observed soundings in the following discussion are taken at the grid point located nearest the station where the observations were made. Since the horizontal grid in- crements are $10 \mathrm{~km}$, the model profile does not coincide exactly with the location of the station. For this reason the initial model profiles will not match exactly with the observed soundings. From Fig. 6 it is clear that the model simulated the evolution of the potential temperature profile well in the lowest $2000 \mathrm{~m}$ in the three simulations shown. At the end of the 12-h simulation, the model-generated potential temperatures are within $1 \mathrm{~K}$ of the observations. The largest errors occur in the lowest $600 \mathrm{~m}$.

Figure 7 shows a time series of screen-height temperature and modeled snow depth at Amarillo. The simulated temperatures are seldom more than $2 \mathrm{~K}$ from the observed values, and usually within $1 \mathrm{~K}$. The shallow snow begins to decrease slowly during the morning as solar radiation is absorbed, then rapidly decreases once the air temperatures rise above freezing. The snow melts fastest in simulation 2 because the vegetation has been replaced with all shrubs in this case. In simulation 3, the vegetation is all grass that protrudes more than the crop stubble that is present in the control run; therefore, the snow also melts faster in simulation 3. Since mul- 


\section{2:00 UTC 18 March 1988 Snow Depth (m)}
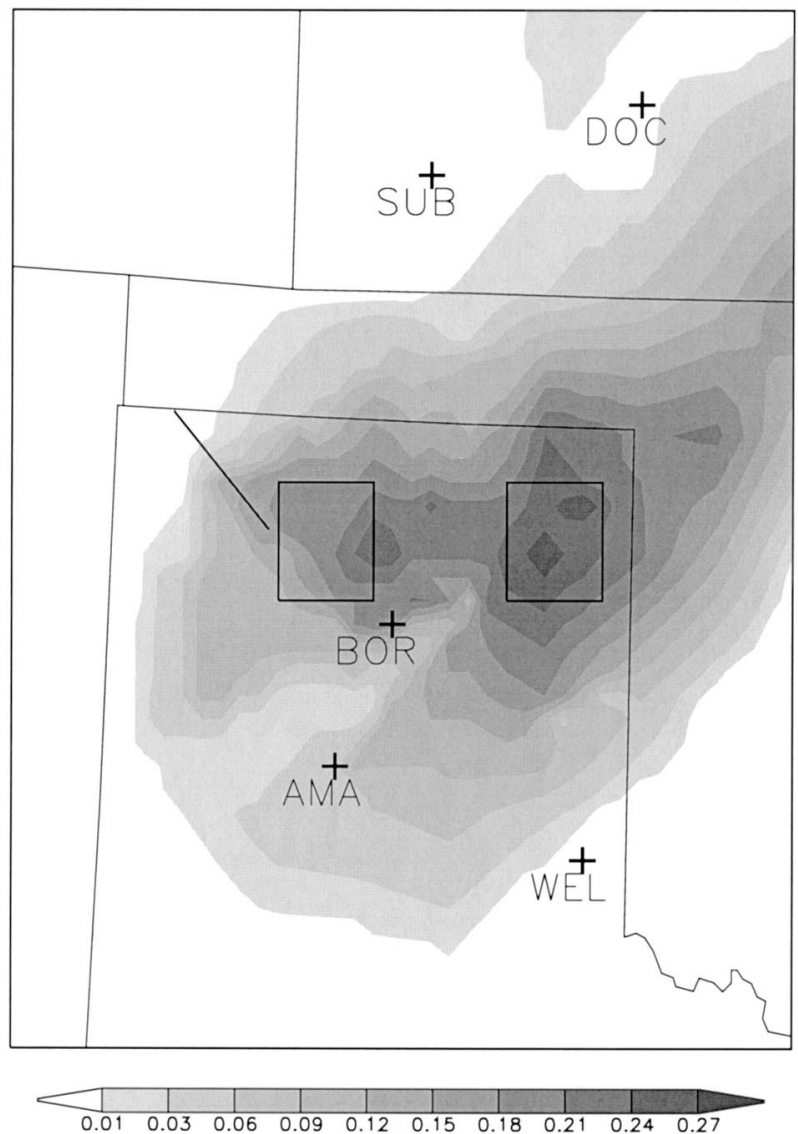

FIG. 5. Snow depth (m) at model initialization time (1200 UTC 18 Mar 1988). Locations of Amarillo, TX; Borger, TX; Wellington, TX; Dodge City, KS; and Sublette, KS, are shown by crosses marked AMA, BOR, WEL, DOC, and SUB, respectively. The black line shows the location of the SSBLIM flight track. The left box shows the location of region 1 and the right box shows location of region 2 .

tiple vegetation types occur in the control run, the snow depth plotted is an area-weighted average of the depths for each of the patches. When the mass of snow in a given patch reaches a minimum value for computational stability of the thermal conduction formulation in LEAF-2 the snow is brought into thermal equilibrium with the top soil layer. This often causes the snow depth to decrease rapidly to zero and explains the stepwise depth decrease that occurs in the control run.

\section{2) Dodge City}

Potential temperature profiles at Dodge City, Kansas, for the same times are also shown in Fig. 6. The model potential temperature is generally within $2 \mathrm{~K}$. There are virtually no differences among the simulations in this case since the Olson shrub-grass mixture is not present at this location, meaning there was little difference in land cover between the simulations. In this case the model profile is too warm at all levels
TABLE 3. Correlation coefficients between the observations at Amarillo, TX, (AMA) and Dodge City, KS, (DOC) and the output for the various simulations. The correlation coefficients for the potential temperature profiles are for heights less than $2000 \mathrm{~m}(N=6)$. The coefficients for the screen-height temperatures were derived from hourly temperature measurements taken during the period of the simulation $(N=13)$.

\begin{tabular}{lccccc}
\hline \hline \multirow{2}{*}{ Model run } & \multicolumn{2}{c}{$\begin{array}{c}\text { Potential temperature } \\
\text { profiles }(z<2000 \mathrm{~m})\end{array}$} & & \multicolumn{2}{c}{ Screen-height temp } \\
\cline { 2 - 3 } \cline { 5 - 6 } & AMA & DOC & & AMA & DOC \\
\hline Control & 0.987 & 0.896 & & 0.993 & 0.996 \\
Simulation 2 & 0.987 & 0.907 & & 0.981 & 0.994 \\
Simulation 3 & 0.990 & 0.899 & & 0.990 & 0.995 \\
\hline
\end{tabular}

below $2000 \mathrm{~m}$. By 0000 UTC significant warming$8 \mathrm{~K}$-has occurred above the base of the inversion in both the model and observed profiles. This is likely the result of subsidence from the nearby high pressure system. Subsidence ranging from 2 to $6 \mathrm{~cm} \mathrm{~s}^{-1}$ occurs in the model over the region during the entire simulation. Looking at the initial model profile we see that it is $1-2 \mathrm{~K}$ too cool in the $200-600-\mathrm{m}$ height range. Figure 7 shows that the simulated screen-height temperature in all of the simulations is generally within $1 \mathrm{~K}$ of the observed values.
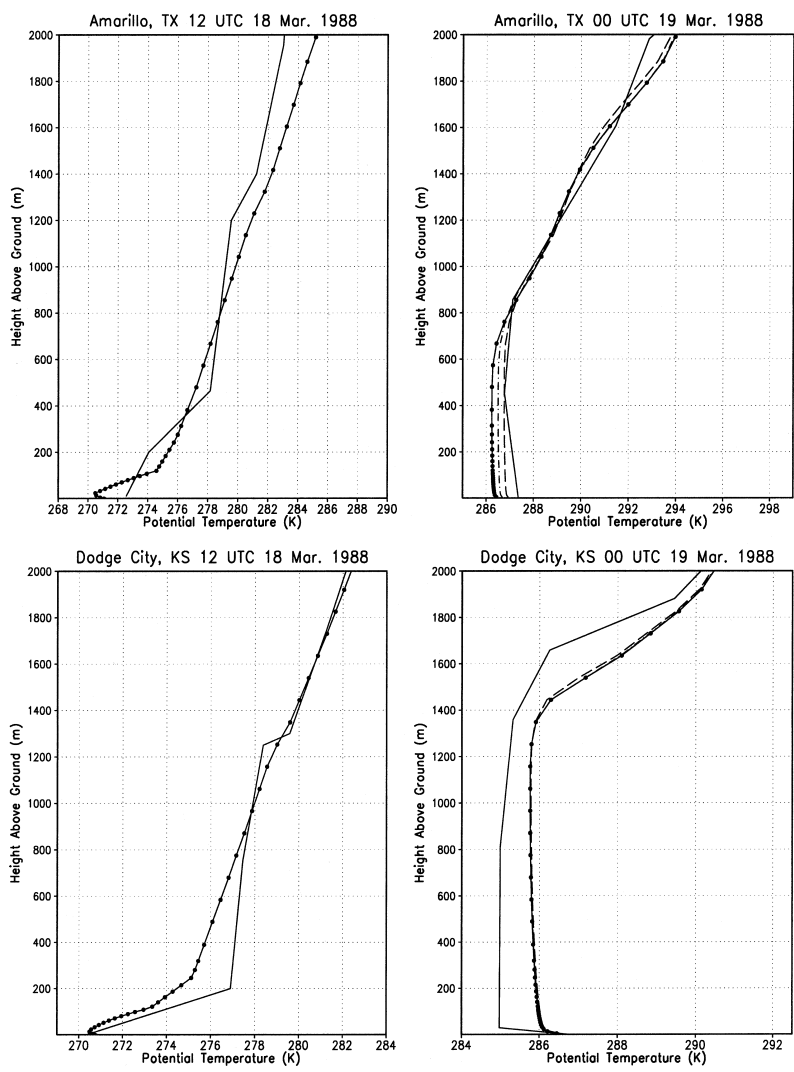

FIG. 6. Comparison of modeled potential temperature profiles with observations for (top) AMA and (bottom) DOC. Solid line is for observed, line with solid circles is for control run, dashed line is for simulation 2, and dash-dot line is for simulation 3. 

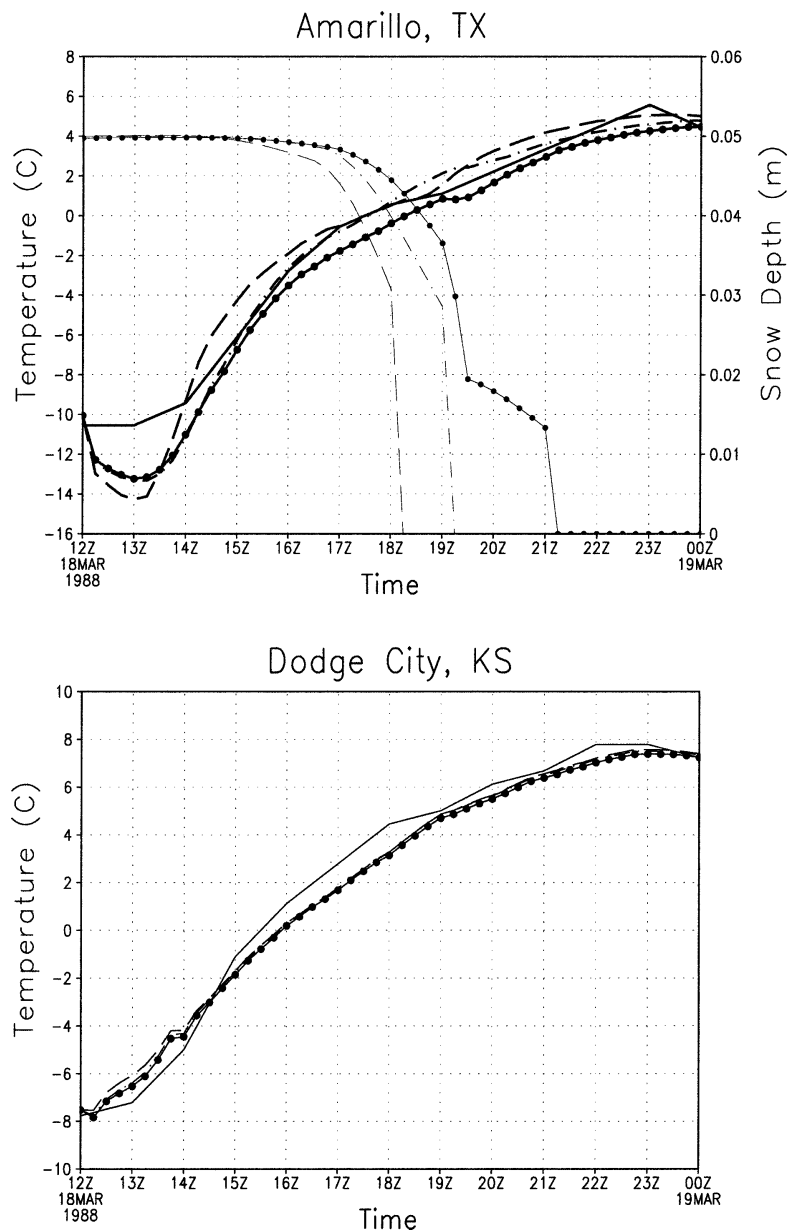

FIG. 7. Comparison of modeled screen-height temperatures with observations for (top) AMA and (bottom) DOC. Solid line is for observed, line with solid circles is for control run, dashed line is for simulation 2, and dash-dot line is for simulation 3. Thin lines in the top panel represent modeled snow depth in each of the simulations.

\section{3) Secondary Stations}

Unfortunately, there were no stations besides Amarillo, Texas, and Dodge City, Kansas, that recorded continuous hourly temperatures during the time of interest. However, three cooperative observer stations-Borger, Texas; Wellington, Texas; and Sublette, Kansas-recorded 0000 UTC temperatures and snow depths (Table 4). The control run temperatures at these stations are within $1-2 \mathrm{~K}$ of those observed. While the snow is observed to completely melt away at Borger, a small amount remains in each of the simulations. Since Borger does not record snow depth at the time the model was initialized, the initial snow depth in the model at this location was interpolated, and may have been too large.

\section{b. Comparison with SSBLIM observations}

Since the evolution of air temperature and boundary layer structure is controlled by the surface sensible and latent heat fluxes, it is also important that they be verified against observations. Observations of sensible and latent heat fluxes along the flight path shown in Fig. 5 are compared to those generated by the model. Potential temperature and surface albedo measured along this flight path are also compared with the model output. The correlation coefficients between these observations and the various simulations are shown in Table 5.

Figure 8 shows sensible and latent heat fluxes as measured by the eddy covariance technique along the 90-m altitude flight track shown in Fig. 5. The black bar at the bottom of each panel represents the part of the flight track that was over snow. The gray bars indicate the snow-covered area in the model. Two 90-m altitude flights were made over the snow on the afternoon of 18 March 1988. During the first flight the sensible heat fluxes ranged from $\sim 210 \mathrm{~W} \mathrm{~m}^{-2}$ over the snow-free areas to $20 \mathrm{~W} \mathrm{~m}^{-2}$ over the snow-covered regions. From Fig. 8 it can be seen that the control run sensible heat fluxes at $90 \mathrm{~m}$ are mostly within 40 $\mathrm{W} \mathrm{m} \mathrm{m}^{-2}$ of the observed values. The largest errors, around $80 \mathrm{~W} \mathrm{~m}^{-2}$, are near the observed snow-nosnow boundary. This could be due to the fact that the snow-covered region in the model extends past the observed boundary. In simulation 2 the sensible heat fluxes are greater than those observed over the snow because of the protruding shrubs. Similarly, the sensible heat fluxes in simulation 3 are greater over the snow than those observed because of the increase in grass, which protrudes more than the stubble and wheat, over the area. Figure 8 shows similar results for the sensible heat flux during the second flight.

In Fig. 8 we can see that the observed latent heat flux is highest over the snow-no-snow boundary. The smallest values of $\sim 20 \mathrm{~W} \mathrm{~m}^{-2}$ are observed over the snow-free area, with slightly higher values, around

TABLE 4. Comparison of the modeled and observed 0000 UTC 18 Mar 1988 screen-height temperatures and snow depths for three secondary surface stations.

\begin{tabular}{|c|c|c|c|c|c|c|}
\hline & \multicolumn{2}{|c|}{ Borger, TX } & \multicolumn{2}{|c|}{ Sublette, KS } & \multicolumn{2}{|c|}{ Wellington, TX } \\
\hline & $\begin{array}{l}\text { Screen-height } \\
\text { temp }\left({ }^{\circ} \mathrm{C}\right)\end{array}$ & Snow depth (m) & $\begin{array}{l}\text { Screen-height } \\
\text { temp }\left({ }^{\circ} \mathrm{C}\right)\end{array}$ & Snow depth (m) & $\begin{array}{l}\text { Screen-height } \\
\text { temp }\left({ }^{\circ} \mathrm{C}\right)\end{array}$ & Snow depth (m) \\
\hline Observed & 3 & 0.00 & 6 & 0.00 & 5 & 0.00 \\
\hline Control & 4 & 0.03 & 8 & 0.00 & 6 & 0.00 \\
\hline Simulation 2 & 5 & 0.01 & 9 & 0.00 & 7 & 0.00 \\
\hline Simulation 3 & 5 & 0.06 & 8 & 0.00 & 6 & 0.00 \\
\hline
\end{tabular}


TABLE 5. Correlation coefficients between the SSBLIM observations and the model values for the various simulations shown in Figs. 8 and $9(N=6)$.

\begin{tabular}{|c|c|c|c|c|c|c|c|c|}
\hline \multirow[b]{2}{*}{ Model run } & \multicolumn{2}{|c|}{ Sensible heat flux } & \multicolumn{2}{|c|}{ Latent heat flux } & \multicolumn{2}{|c|}{ Potential temp } & \multicolumn{2}{|c|}{ Albedo } \\
\hline & Flight 1 & Flight 2 & Flight 1 & Flight 2 & Flight 1 & Flight 2 & Flight 1 & Flight 2 \\
\hline Control & 0.933 & 0.803 & 0.804 & 0.959 & 0.982 & 0.959 & 0.967 & 0.845 \\
\hline Simulation 2 & 0.946 & 0.772 & 0.916 & 0.928 & 0.980 & 0.959 & 0.845 & 0.674 \\
\hline Simulation 3 & 0.912 & 0.788 & 0.865 & 0.823 & 0.978 & 0.958 & 0.851 & 0.528 \\
\hline
\end{tabular}

$30-40 \mathrm{~W} \mathrm{~m}^{-2}$, over the snow-covered area. The maximum over the snow-no-snow boundary region may be due to warmer and drier air from the snow-free region being advected over the melting snow by the northwesterly winds. The model correctly simulates the maximum over the snow-no-snow boundary and minimum over the snow-free areas in the control run. The model is generally within $10-20 \mathrm{~W} \mathrm{~m}^{-2}$ of the observed values. The worst errors occur over the snow where the model underestimates the fluxes by as much as $40 \mathrm{~W} \mathrm{~m}^{-2}$. The latent heat fluxes in simulations 2 and 3 are greater because of the greater sensible heat fluxes and turbulent transfer. The latent heat flux patterns during the second flight were similar to those in the first flight (Fig. 8).

Comparisons of flight-level potential temperature and surface albedo for the two flights are shown in Fig. 9. From the top left panel of Fig. 9, it can be seen that the observed potential temperature ranges from as high as
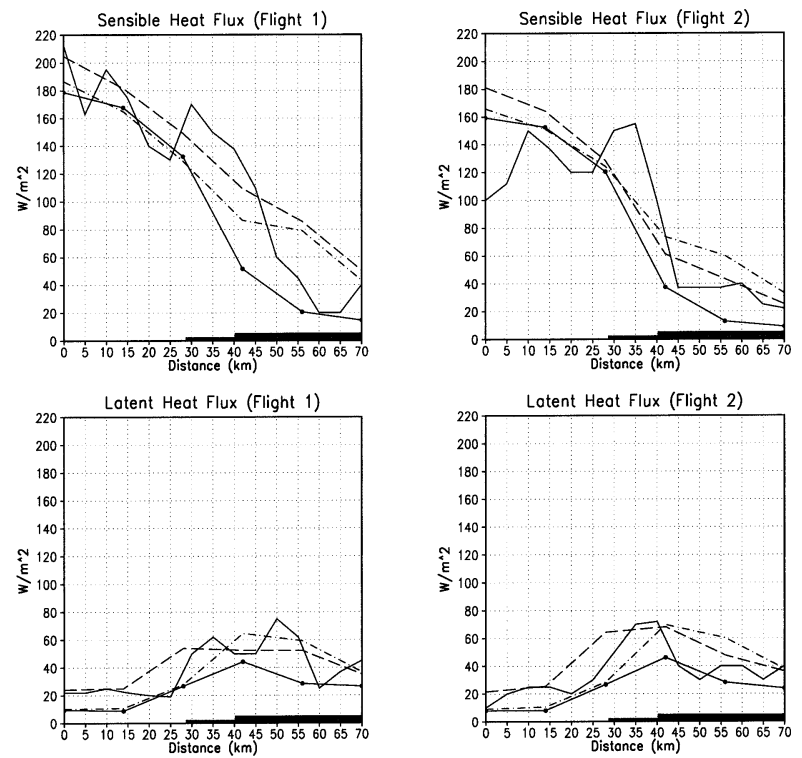

Fig. 8. (top) Sensible and (bottom) latent heat flux along the (left) first (2013-2028 UTC) and (right) second (2121-2136 UTC) 90-m altitude SSBLIM flights. Solid line is for observed, line with solid circles is for control run, dashed line is for simulation 2, and dashdot line is for simulation 3 . The gray and black bars along the distance axis of each panel shows the portion of the flight over snow as modeled and observed, respectively.
$290 \mathrm{~K}$ over the snow-free areas to as low as $284 \mathrm{~K}$ over the snow. The simulated values at $90 \mathrm{~m}$ in the control run are generally within $1 \mathrm{~K}$ of the observed values. The largest errors are once again over the snow-snowfree boundary region. In this region the model-simulated temperatures are too cool, likely due to the underpredicted sensible heat flux there. The potential temperatures in both simulations 2 and 3 are greater over the snow because of the greater sensible heat fluxes generated by the protruding vegetation. The bottom left panel of Fig. 9 shows that the net surface albedo as measured by the aircraft ranges from a low of around 0.2 over the snow-free areas to as high as 0.65 over the snow. The simulated albedo in the control run is also right around 0.2 over the snow-free region. Over the snow-covered region the model albedo in the control run reaches a high of about 0.5 , which appears to be a bit high on average, but is still a reasonable approximation of the albedo in the snow area. The albedo in simulations 2 and 3 are lower because of the greater amount of protruding vegetation. As seen in Fig. 9, the observed albedo of the snow-covered area varies quite rapidly from as low as 0.3 to as high as 0.65 , illustrating
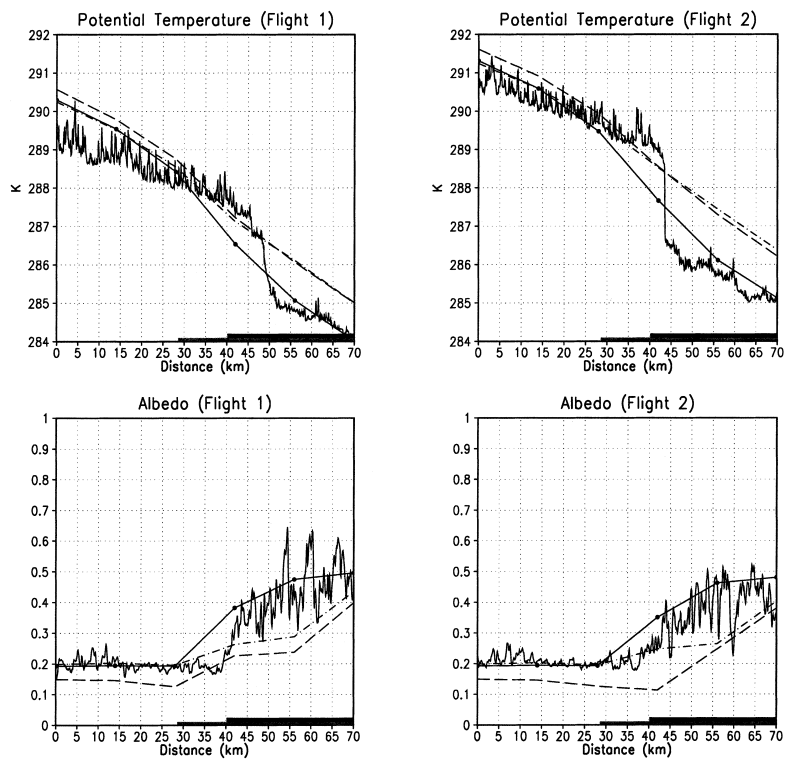

FIG. 9. Same as Fig. 8 except for 90-m-altitude potential temperature and surface albedo. 
the likely high degree of surface land-cover heterogeneity and snow depth variability in the region. The 10$\mathrm{km}$ grid cells of the model will not be able to resolve such rapid variations in snow depth, since LEAF-2 does not yet parameterize the subgrid-scale snow depth variability, and so an average value for the albedo is the best that can be done. The patterns of albedo and potential temperature during the second flight were similar to those in the first flight (Fig. 9).

\section{c. Deep snow regions}

The differences between simulations 2 and 3 and the control will be examined over two regions, shown by the squares in Fig. 5, of the fine domain. Since the results of simulation 4 are very similar to those of simulation 3 , they are not discussed. Each of the regions are 50 $\mathrm{km} \times 50 \mathrm{~km}$. The western region, which will be called region 1 , is located over an area consisting predominately of cropland and short grass according to the Landsat data; see Fig. 10. The eastern region, which will be called region 2 , consists of mostly short grass with a few areas of shrubs and cropland; see Fig. 11.

\section{1) Simulation 2}

In simulation 2, the AVHRR-derived land-cover data have been used with the OGE classes 40 and 41, the shrub-grass mixture classes, cross referenced to deciduous shrubs. Everything else has remained the same as in the control run. Figures 10 and 11 show the fractional land-cover breakdown for the two regions as defined from the AVHRR data used in simulation 2. Region 1 is now mostly shrubs, with virtually no short grass, and the crop areas, defined as crop stubble or winter wheat, are also significantly less (Fig. 10). On the other hand, region 2 is now mostly shrubs instead of short grass, and the crop areas have increased slightly (Fig. 11). The effects of these land-cover changes on surface sensible and latent heat fluxes, air temperature, snowmelt, and boundary layer structure in the two regions are discussed below.

\section{(i) Region 1}

In this case, the switch from Landsat to AVHRR landcover data, and the choice of cross referencing the shrub-grass mixture to all shrubs, has significantly reduced the crop and short grass areas as shown in Fig. 10. The average snow depth in region 1 at model initialization time is about $0.19 \mathrm{~m}$. Referring back to Table 2 it can be seen that the crop areas will be completely masked by snow of this depth, while the short grass will be partially masked, and the shrubs mostly exposed. Since, in this case, the shrub fraction has increased at the expense of short grass and crops, we expect that higher sensible heat fluxes will occur in simulation 2 than in the control run. The taller protruding shrubs will emit most of the solar energy that they absorb in the form of upward turbulent sensible heat flux.

Figure 12 confirms that this is indeed the case. The top-left panel shows the evolution of the area-averaged surface sensible heat flux from region 1 . The surface sensible heat fluxes for the control run and simulation 2 both increase from negative values around sunrise to maximum positive values in the early afternoon, and then decrease to near 0 by early evening. However, the morning increase is much more rapid in simulation 2 , and the sensible heat flux is some $60-80 \mathrm{~W} \mathrm{~m}^{-2}$ greater than in the control simulation for much of the day. This is what is expected since the tall shrubs protrude through the snow in simulation 2 allowing for more solar radiation to be absorbed during the course of the day. The sensible heat flux in simulation 2 peaks and begins to decrease earlier in the afternoon than in the control run since the sparse shrubs have a lower heat capacity than the snow.

The bottom left panel of Fig. 12 shows the evolution of the area-averaged latent heat flux over the course of the day. The latent heat flux in this case will be due almost solely to evaporation of moisture from the snow and soil surfaces. Transpiration is virtually nonexistent because the vegetation is either dead or senescent. The latent heat flux increases much more rapidly in simulation 2 than in the control run during the morning (Fig. 12). This is likely a result of the higher surface sensible heat flux increasing the turbulent transfer. The latent heat flux begins to decrease in the early afternoon, around 1900 UTC, because in some areas the snow has already completely melted, meaning that the supply of moisture for evaporation has been reduced. The small spike in sensible heat flux right after 1900 UTC in simulation 2 is also a result of the emergence of snow-free areas. In contrast, in the control simulation the latent heat flux initially increases much more slowly than in simulation 2 and, following the sensible heat flux, peaks later in the afternoon.

The evolution of the area-averaged 5-m air temperature and snow depth is plotted in Fig. 13. In the top left panel it can be seen that the air temperature in simulation 2 is as much as $6^{\circ} \mathrm{C}$ warmer than in the control run during the midmorning. This is a direct result of the much greater surface sensible heat flux during this time in simulation 2. The difference in air temperature between the two simulations decreases by midday, possibly because of advection of warmer air from the snow-free areas to the northwest by the prevailing northwesterly flow. The bottom-left panel of Fig. 13 shows that more of the snow melts in simulation 2. Also, the total amount of longwave, shortwave, and sensible heat energy absorbed by the snow is between 50 and $100 \mathrm{~W}$ $\mathrm{m}^{-2}$ greater during the course of the day in simulation 2 than in the control simulation (Fig. 14). The amount of solar radiation absorbed by the snow in simulation 2 is actually less than in the control run because of the shading effect of the protruding shrubs; see Fig. 14. 

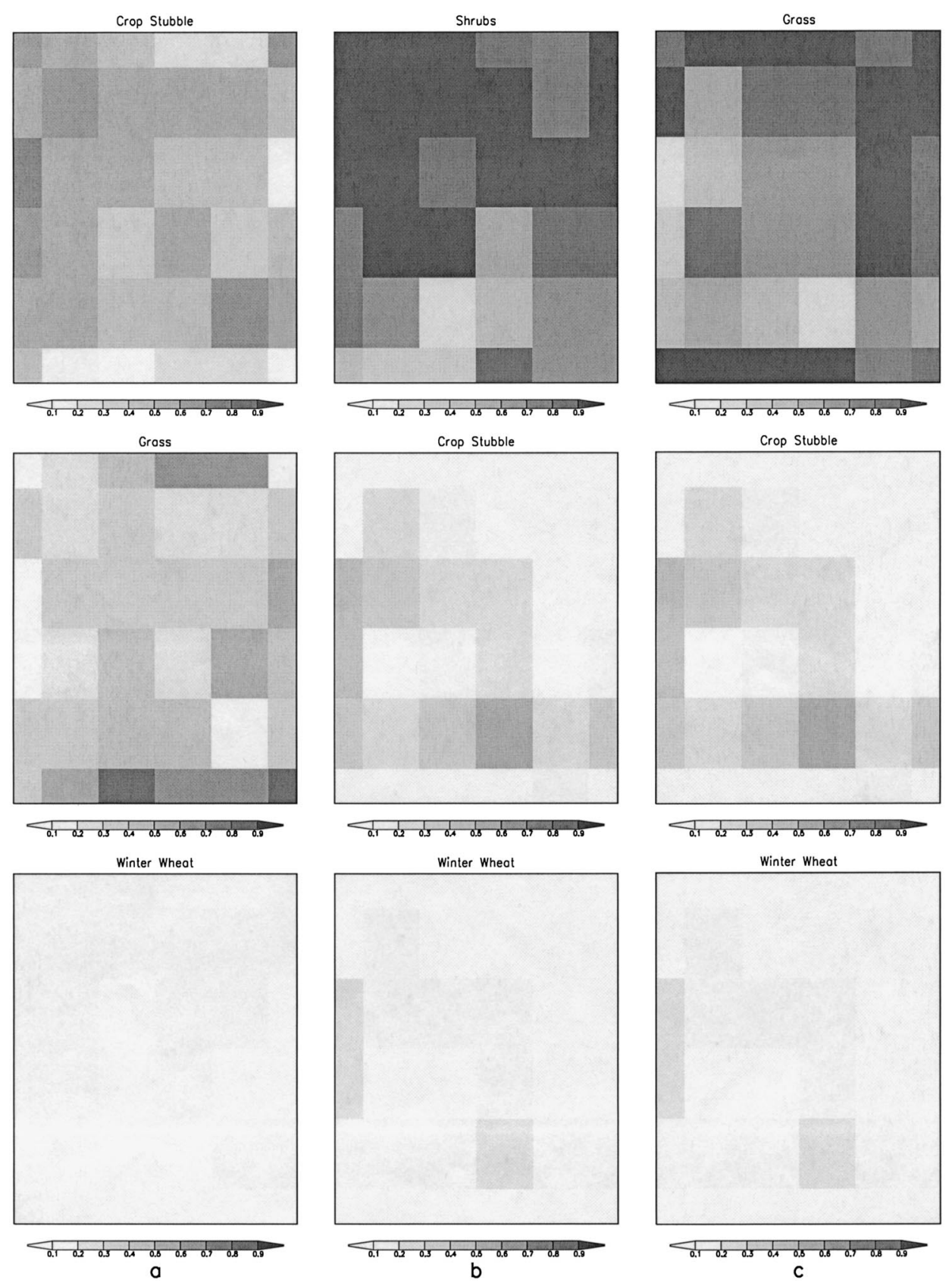

FIG. 10. Fraction of each grid cell in region 1 that is occupied by the major land-cover categories as determined from (a) Landsat data (control run), (b) AVHRR data with the shrub-grass mixture defined as all shrubs (simulation 2), and (c) AVHRR data with the shrub-grass mixture defined as all grass (simulation 3 ).

However, the increased longwave and sensible heat fluxes from the protruding vegetation in simulation 2 more than offset the reduction in absorbed solar radiation, leading to a net increase in the amount of energy absorbed by the snow in simulation 2 .

Finally, our results indicate that the midafternoon boundary layer is about $300 \mathrm{~m}$ deeper in simulation 2 than in the control run (Fig. 15), another consequence of the increased sensible heat flux. Also, the profile in simulation 2 is about $1 \mathrm{~K}$ warmer than the control run near the surface. Above about $1000 \mathrm{~m}$ there is little difference between the two simulations, which illustrates that the land-cover effects, not surprisingly, are most significant near the surface.

\section{(ii) Region 2}

In region 2, the grass was replaced with shrubs, and the area of cropland has increased slightly compared to 

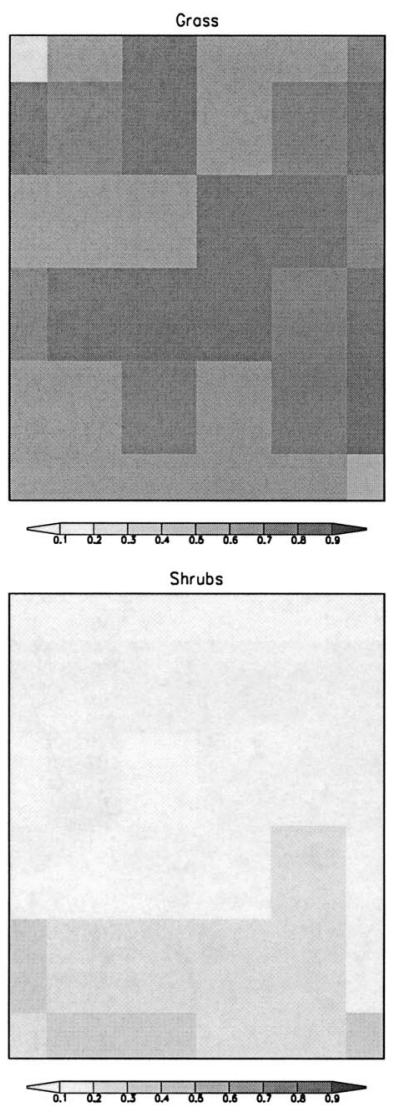

Crop Stubble
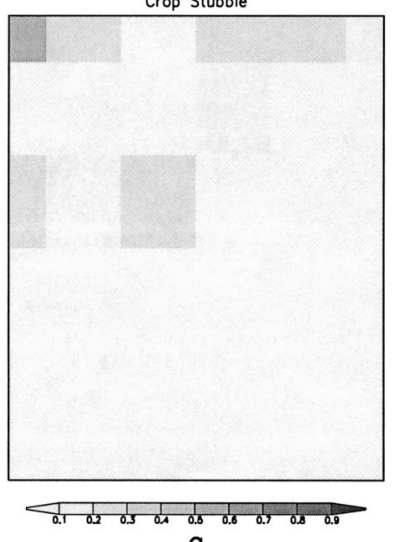

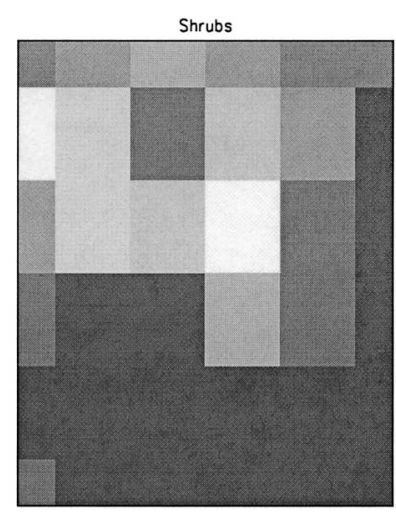

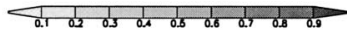

Crop Stubble
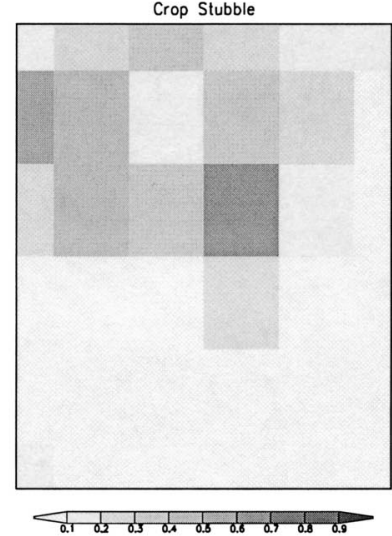

Winter Wheot

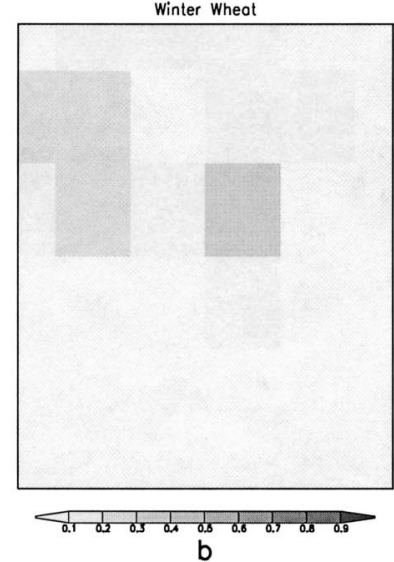

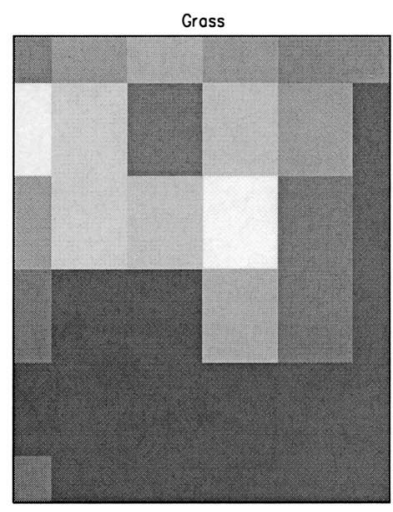

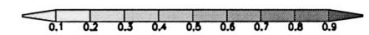

Crop Stubble
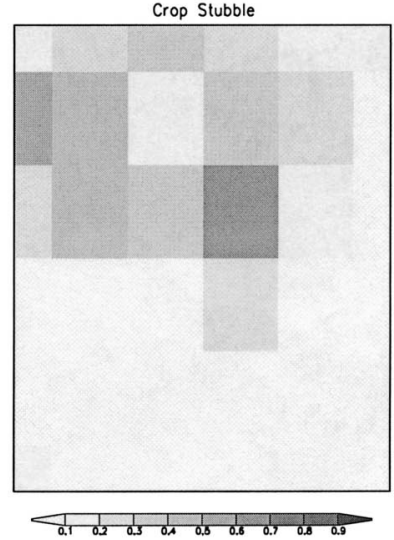

Winter Wheat

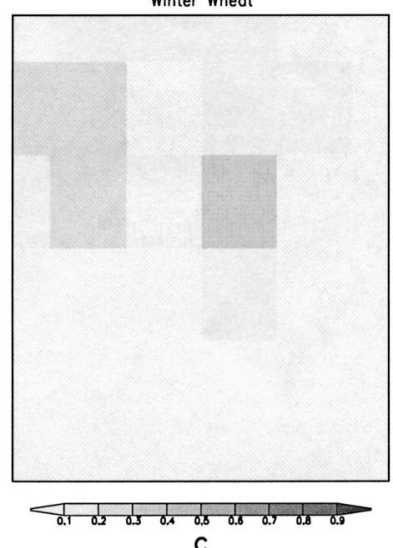

FIG. 11. Same as Fig. 10 except for region 2.

the cropland area in the control run (Fig. 11). From the canopy heights listed in Table 2 it can be seen that over most areas in region 2 there is now more protruding vegetation because of the shrubs. The average snow depth at initialization time in region 2 is about $0.25 \mathrm{~m}$. This means that in the control run all the vegetation on average would have been buried. In contrast, in simulation 2 protruding shrubs cover over $80 \%$ of some grid cells in region 2.

The results of this land-cover change in region 2 are similar to those just discussed for region 1 (Figs. 1216). This is to be expected since in both regions the primary effect of the land-cover change is to increase the coverage of protruding shrubs at the expense of shorter grass and crop stubble.

\section{2) Simulation 3}

In this simulation the AVHRR-derived land cover is used with the OGE grass-shrub mixture defined as all 

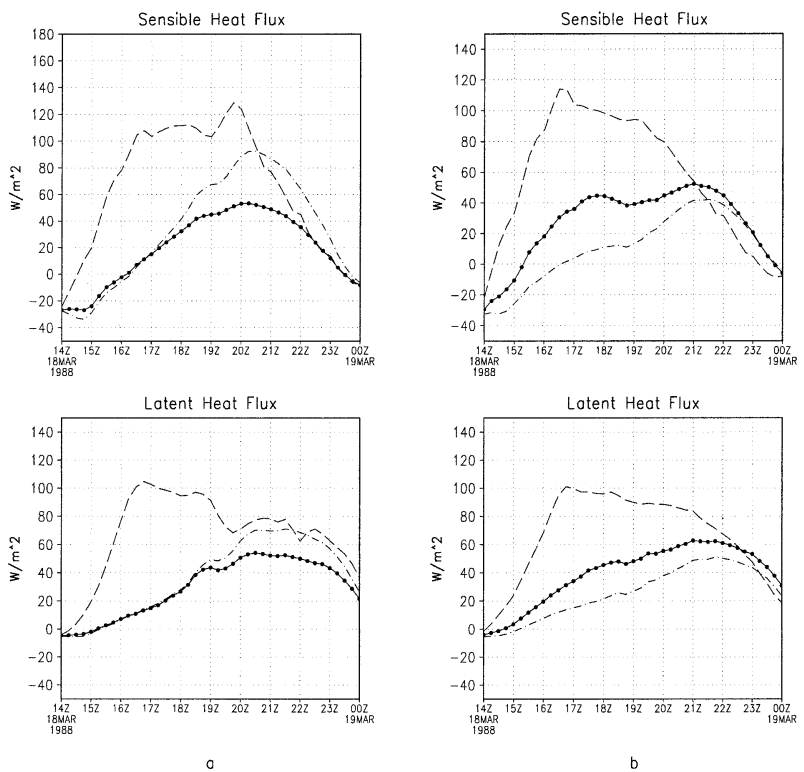

FIG. 12. (top) Area-averaged sensible and (bottom) latent heat fluxes over (a) region 1 and (b) region 2. Line with solid circles is for control run, dashed line is for simulation 2, and dash-dot line is for simulation 3 .

grass, as is done by default in RAMS 4.30. The main effect of this change in region 1 is to increase the amount grass at the expense of crop stubble and winter wheat; see Fig. 10. The changes in region 2 are slight in this simulation with only a small increase in crop areas and the removal of the small shrub fraction that was present in the Landsat data; see Fig. 11. The effects of these changes on the surface heat fluxes, air temperature, snow depth, and boundary layer structure are discussed below. This discussion also applies to simulation 4 since the results of that simulation were so similar.

\section{(i) Region 1}

Since the land-cover change in this simulation has increased the amount of protruding vegetation in region 1 , higher sensible heat fluxes are expected. The top-left panel of Fig. 12 shows that this is indeed the case. The average snow depth at model start time in region 1 is $0.19 \mathrm{~m}$ meaning the grass with canopy height of $0.2 \mathrm{~m}$ protrudes slightly. In the control run there is more crop stubble and winter wheat, which are assumed to have canopy heights of 0.05 and $0.1 \mathrm{~m}$, respectively. This vegetation is easily masked at the start of the simulation. Figure 12 shows that the maximum surface sensible heat flux in this case is about $40 \mathrm{~W} \mathrm{~m}^{-2}$ higher in simulation 3 than in the control run. The bottom-left panel of Fig. 12 shows that the latent heat flux peaks about $20 \mathrm{~W}$ $\mathrm{m}^{-2}$ higher in simulation 3 than in the control run. The surface sensible and latent heat fluxes for simulation 3 are both less than those in simulation 2, reflecting the smaller volume of protruding material in simulation 3 .
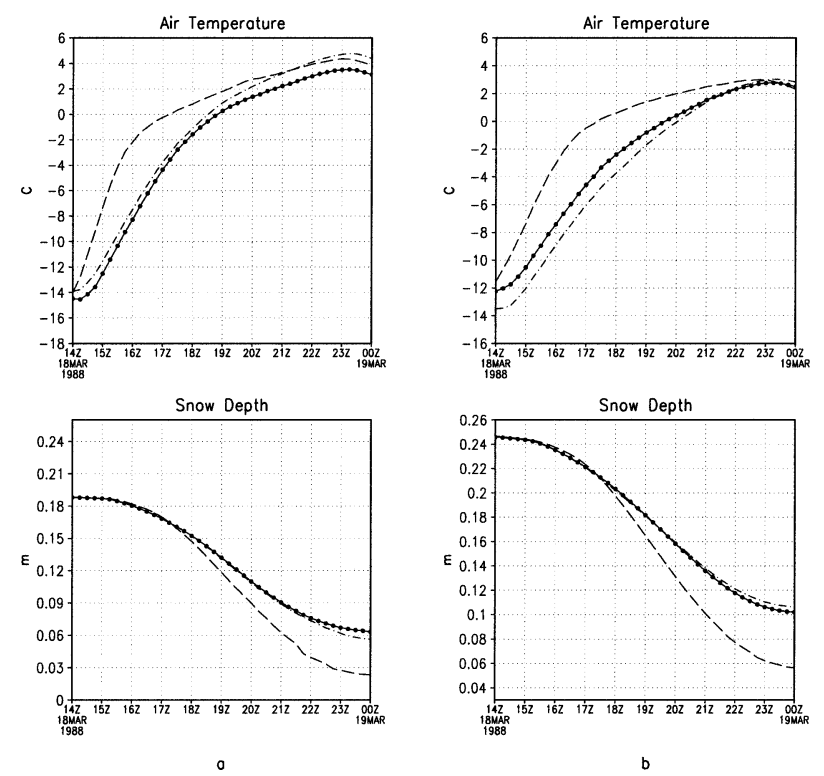

FIG. 13. (top) Area-averaged 5-m temperature and (bottom) snow depth over (a) region 1 and (b) region 2. Line with solid circles is for control run, dashed line is for simulation 2, and dash-dot line is for simulation 3 .

The top-left panel of Fig. 13 shows that the maximum daytime temperature peaks about $1^{\circ} \mathrm{C}$ higher than in the control run. In this case there is not much difference in snowmelt as shown by the curves in the bottom-left panel of Fig. 13. There is little difference in the total absorbed energy between simulation 3 and the control run (Fig. 14), although the higher sensible heat flux does deepen and warm the boundary layer to some extent (Fig. 15).

\section{(ii) Region 2}

By removing the shrubs and increasing cropland, the amount of protruding vegetation in this case has been reduced. The effects of this on the sensible heat flux is shown in the top-right panel of Fig. 12. The sensible heat flux does not increase as rapidly in the morning and peaks slightly lower than in the control run. The latent heat flux is similarly reduced as shown in the bottom-right panel of Fig. 12. The reduction in sensible heat flux leads to a slight decrease in morning air temperatures as shown in the top-right panel of Fig. 13. The bottom-right panel of Fig. 13 shows that there is only a slight decrease in snowmelt in this case. Figure 16 shows that the total amount of longwave, shortwave, and sensible heat fluxes absorbed by the snow is slightly less in simulation 3 than in the control run. The amount of shortwave radiation absorbed is greater in simulation 3 because there is less protruding vegetation to shade the surface. However, the reductions in longwave and sensible heat fluxes more than offset the increase in solar radiation leading to a net decrease in the amount of 

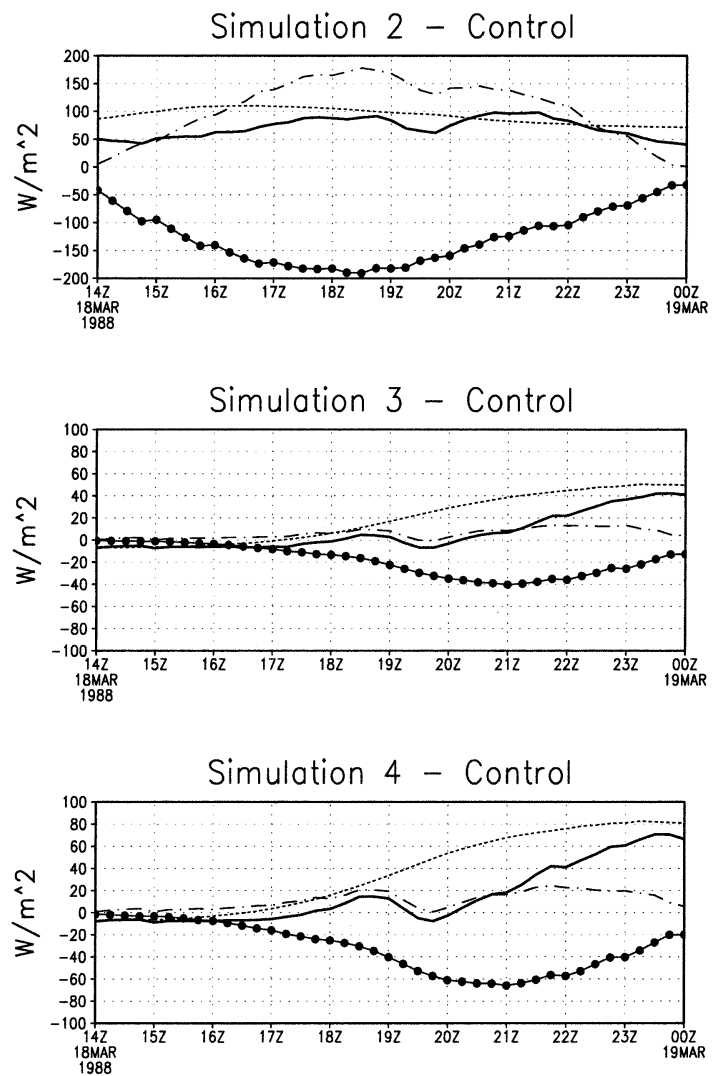

$$
\text { ........ Longwave } \rightarrow \text { - Shortwave }- \text { - Sensible } \longrightarrow \text { Total }
$$

FIG. 14. The differences (simulation - control) in longwave, shortwave, and sensible heat fluxes absorbed by the snow from the control run for each of the simulations over region 1 . These values were obtained by subtracting the area-averaged control run values from the area-averaged values for the other three simulations. The longwave radiation includes components from both the atmosphere and the vegetation.

energy absorbed by the snow in simulation 3. From Fig. 15 it is seen that there is little difference in boundary layer temperature and depth.

\section{Concluding remarks}

\section{a. Summary and conclusions}

The ability of snow to suppress daytime temperatures depends upon the degree to which it is able to mask the land cover. Protruding vegetation absorbs solar radiation, warms, and emits upward turbulent heat flux. This will lead to higher air temperatures and a deeper boundary layer. In contrast, lower temperatures will occur over a region where snow completely buries the vegetation and limits the surface temperature to $0^{\circ} \mathrm{C}$. This means that the accuracy of daytime air temperatures simulated by a model will be dependent upon how representative the land cover in the model is.
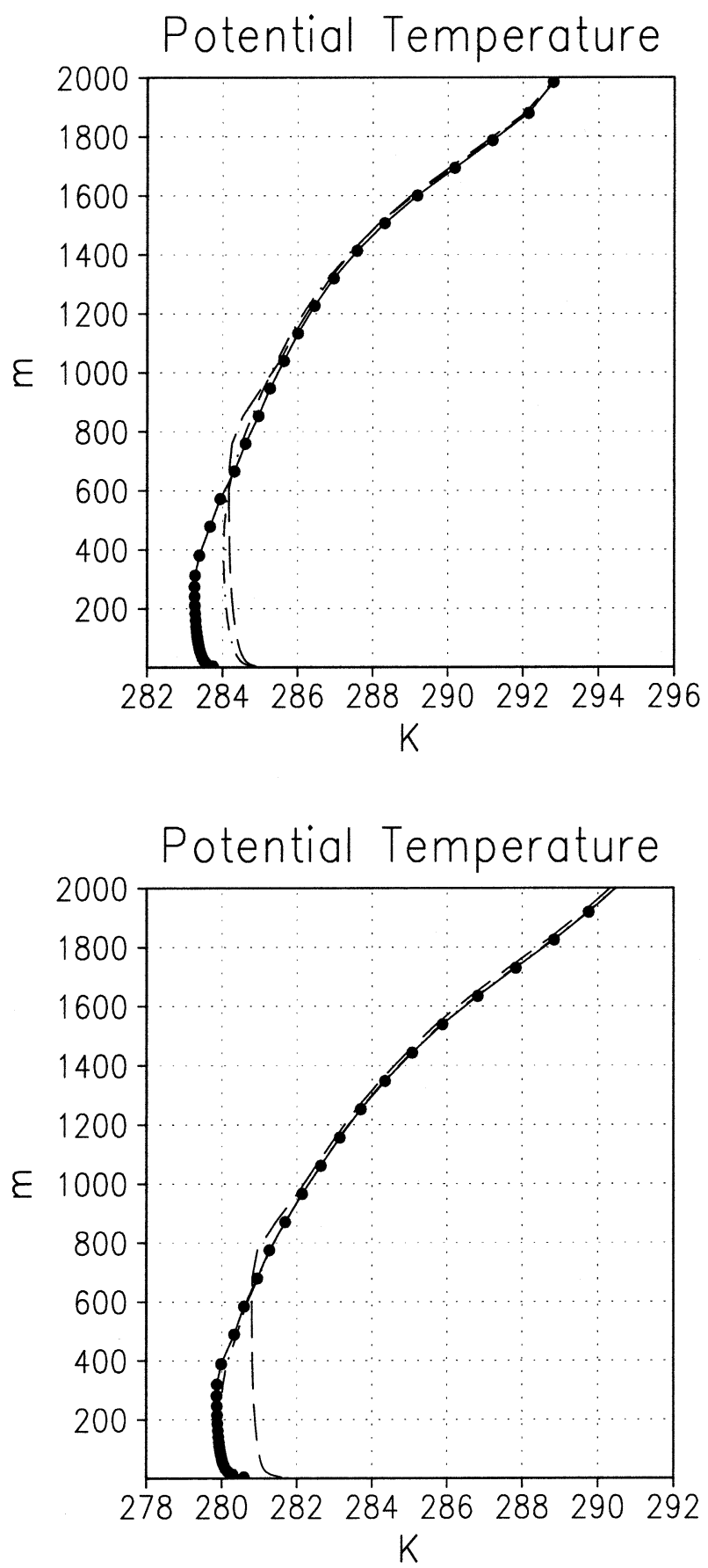

FIG. 15. Area-averaged 2100 UTC potential temperature profile for (top) region 1 and (bottom) region 2. Line with solid circles is for control run, dashed line is for simulation 2, and dash-dot line is for simulation 3 .

In this study we have investigated the sensitivity of RAMS-generated surface sensible and latent heat fluxes, air temperature, snowmelt rate, and boundary layer structure to the land-cover representation used. A control simulation was first performed using the best rep- 

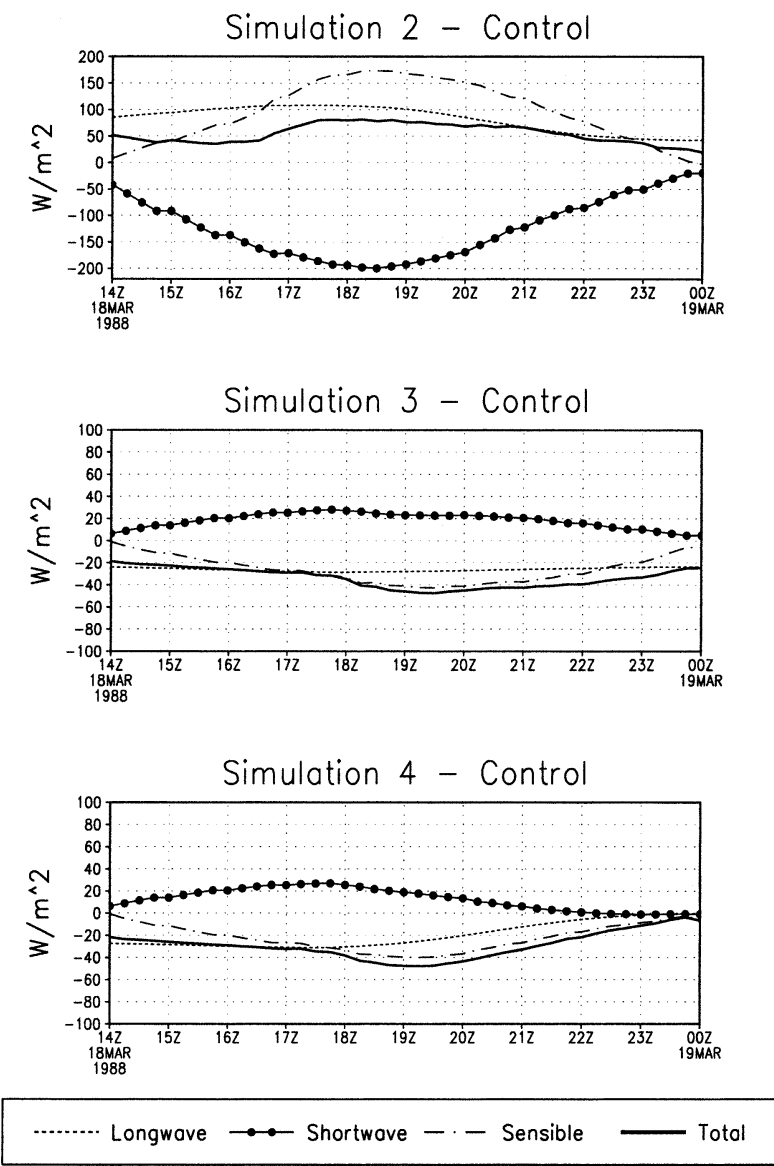

FIG. 16. Same as Fig. 14 except for region 2.

resentation of the current landscape. The results of this control were verified against observations from ground stations and the SSBLIM aircraft. Three additional simulations, each with a different land-cover representation, were then run and the results compared with the control run.

In simulation 2 the AVHRR-derived land cover was used with the Olson grass-shrub mixture defined as all shrubs. This change led to much higher sensible heat fluxes and air temperatures over a region that was predominantly crops in the control run. Similar results were found for a region that was mainly grass in the control run. The primary effect of this land-cover change was to increase the amount of protruding vegetation in both of the study regions. In simulation 3 the same AVHRRderived land cover was also used, but with the Olson grass-shrub class defined as all grass. This produced sensible heat fluxes and air temperatures higher than in the control run but less than in simulation 2 over the predominantly crop area (region 1). The grass in this case protrudes more than the crop stubble and winter wheat but less than the shrubs. Slightly lower sensible heat fluxes and air temperatures occurred over region 2 since the area of crops and grass was slightly larger there in simulation 3. Finally, simulation 4 suggests that converting natural grass land in the Texas Panhandle to crop stubble and winter wheat may lead to cooler daytime temperatures over snow while increased shrubs may lead to warmer temperatures. In region 1 , which is mostly cropland at the present, higher sensible heat fluxes and air temperatures were simulated when the land cover was changed to its natural state. In contrast, in region 2, which has some shrubs at present, lower sensible heat fluxes and air temperatures were simulated when the land cover was changed to its natural state.

The results of this study help to shed light on how sensitive models such as RAMS are to the land-cover representation. From the earlier discussion we can see that the choice of land-cover data can lead to differences in temperature over snow by as much as $6^{\circ} \mathrm{C}$. The height of the afternoon boundary layer over snow can also vary by as much as several hundred meters when different land-cover datasets are used. In addition, the last simulation suggests that anthropogenic land-use change can have a significant impact on local temperatures over snow during the day. This study should point to the need for modelers to exercise care in defining the land cover for weather and climate simulations. The results also illustrate that in simulations of long-term climate a model should be able to predict and represent changes in vegetation patterns. Finally, this study also shows how important it is for weather and climate models to be able to reasonably simulate the evolution of snow depth. If the model cannot accurately simulate changes in snow depth, then it will not have the proper fractions of exposed vegetation and snow, and thus will incorrectly simulate the surface heat balance.

\section{b. Suggestions for future work}

An obvious extension of this work would be to run a seasonal simulation over the northern U.S. Great Plains during winter. This region has undergone many of the same changes in land use that the Texas Panhandle has, namely, introduction of crops and increased woody species in the remaining grass areas. Since snow covers the ground for a larger part of the winter in this region, the daily effects described above will likely add up and produce significantly different seasonal average temperatures and snowmelt rates. There may also be significant differences in average precipitation since the alterations to the surface heat fluxes will influence the boundary layer stability.

Last, some improvements to LEAF-2 should be considered. These include basing the sensible heat flux from the vegetation to the canopy air on a total area index instead of just the LAI and coupling with a plant model to dynamically generate values for LAI, vegetation fraction, canopy height, and albedo. As mentioned previously, LEAF-2 calculates the sensible heat flux from the vegetation to the canopy using the LAI, which in this case is a measure of the green leaf area. In reality, the 
area of branches and dead leaves should also be included since these will warm and emit a turbulent flux as well. This problem is the worst for the case of deciduous species in winter since they will generate little or no heat flux in the current treatment when they are nearly bare of leaves.

Another improvement would be to couple LEAF-2 with a dynamic plant model, such as the General Energy and Mass Transfer Model (GEMTM; Chen and Coughenour 1994) or CENTURY (Parton 1996). These models could be used to calculate LAI, vegetation fraction, canopy height, and albedo from the temperature, precipitation, solar radiation, etc., data predicted by RAMS. These dynamic vegetation parameters could then be fed into LEAF-2 for calculating the various surface fluxes back to RAMS. This would be an improvement, especially for longer-term climate simulations, over the current situation where LEAF-2 prescribes oversimplified seasonal variations to LAI and vegetation fraction and holds the other parameters constant.

Acknowledgments. We would like to acknowledge Dr. Joseph McFadden and Dr. Zhiqiang Gao for help to obtain and process the Landsat TM land-cover data. Also, thanks to Dr. Glen Liston, Dr. Robert Walko, and Dr. Joseph Eastman for their help in using RAMS. Thanks should also be given to Mr. Ron Ruth for his help in obtaining the SSBLIM aircraft data. Finally, thank you to Ms. Dallas Staley for her help in preparing the text of this article in final form.

This work was partially funded by a graduate fellowship from AMS/NASA's Earth Science Enterprise. Additional funding was provided by NOAA Grant NA67RJ0152 Amendment 29, and USGS Contract 99CRAG005 SA 9005CS0014. The NCEP-NCAR reanalysis, U.S. Summary of the Day snow data, upperair observations, and surface observations used to initialize these simulations are provided by the Data Support Section Scientific Computing Division at NCAR. NCAR is supported by grants from the National Science Foundation.

\section{REFERENCES}

Baker, D. G., D. L. Ruschy, R. H. Skaggs, and D. B. Wall, 1992: Air temperature and radiation depressions associated with a snow cover. J. Appl. Meteor., 31, 247-254.

Chen, C., and W. R. Cotton, 1983: A one-dimensional simulation of the stratocumuluscapped mixed layer. Bound.-Layer Meteor., 25, 289-321.

Chen, D.-X., and M. B. Coughenour, 1994: GEMTM: A general model for energy and mass transfer of land surfaces and its application at the FIFE sites. Agric. For. Meteor., 68, 145-171.

Cohen, J., and D. Rind, 1991: The effect of snow cover on climate. J. Climate, 4, 689-706.

Cramer, J., 1988: Observational evaluation of snow cover effects on the generation and modification of mesoscale circulations. Atmospheric Science Paper 439, Colorado State University, Fort Collins, CO, 143 pp.
Dickinson, R. E., A. Henderson-Sellers, P. J. Kennedy, and M. F. Wilson, 1986: Biosphere-Atmosphere Transfer Scheme (BATS) for the NCAR community climate model. Tech. Rep. 275+STR, National Center for Atmospheric Research, Boulder, CO, 69 pp.

Ellis, A. W., and D. J. Leathers, 1998: A quantitative approach to evaluating the effects of snow cover on cold airmass temperatures across the U.S. Great Plains. Wea. Forecasting, 13, 688701.

Greene, E. M., G. E. Liston, and R. A. Pielke Sr., 1999: Relationships between landscape, snowcover depletion, and regional weather and climate. Hydrol. Processes, 13, 2453-2466.

Hartmann, D. L., 1994: Global Physical Climatology. Academic Press, $411 \mathrm{pp}$.

Hatch, S. L., and J. Pluhar, 1993: Texas Range Plants. Texas A\&M University Press, 326 pp.

Huang, J., H. M. Van den Dool, and K. P. Georgakakos, 1996: Analysis of model-calculated soil moisture over the United States (1931-1993) and applications to long-range temperature forecasts. J. Climate, 9, 1350-1362.

Jones, O. R., and T. W. Popham, 1997: Cropping and tillage systems for dryland grain production in the southern high plains. Agron. J., 89, 222-232.

Kalnay, E., and Coauthors, 1996: The NCEP/NCAR 40-Year Reanalysis Project. Bull. Amer. Meteor. Soc., 77, 437-471.

Leathers, D. J., and D. A. Robinson, 1993: The association between extremes in North American snow cover extent and United States temperatures. J. Climate, 6, 1345-1355.

Lee, T. J., 1992: The impact of vegetation on the atmospheric boundary layer and convective storms. Atmospheric Science Paper 509, Dept. of Atmospheric Science, Colorado State University, Fort Collins, CO, 137 pp.

Liston, G. E., 1995: Local advection of momentum, heat, and moisture during the melt of patchy snow covers. J. Appl. Meteor., 34, $1705-1715$

Mellor, G. L., and T. Yamada, 1982: Development of a turbulence closure model for geophysical fluid problems. Rev. Geophys. Space Phys., 20, 851-871.

Namias, J., 1985: Some empirical evidence for the influence of snow cover on temperature and precipitation. Mon. Wea. Rev., 113, $1542-1553$

Olson, J. S., 1994a: Global ecosystem framework-definitions. USGS EROS Data Center Internal Rep., Sioux Falls, SD, 37 pp.

_ 1994b: Global ecosystem framework-translation strategy. USGS EROS Data Center Internal Rep., Sioux Falls, SD, 39 pp.

Otterman, J., M. D. Novak, and D. O'C. Starr, 1993: Turbulent heat transfer from a sparsely vegetated surface: Two-component representation. Bound.-Layer Meteor., 64, 409-420.

Parton, W. J., 1996: The CENTURY model. Evaluation of Soil Organic Matter Models, D. S. Powlson, P. Smith, and J. U. Smith, Eds., NATO ASI Series, Vol. I38, Springer-Verlag, 283-291.

Pielke, R. A., 2002: Mesoscale Meteorological Modeling. 2d ed. Academic Press, 676 pp.

—_ and Coauthors, 1992: A comprehensive meteorological modeling system-RAMS. Meteor. Atmos. Phys., 49, 69-91.

Scifres, C. J., 1980: Brush Management: Principles and Practices for Texas and the Southwest. Texas A\&M University Press, 360 pp.

Sellers, W. D., 1965: Physical Climatology. University of Chicago Press, 272 pp.

Shul'gin, A. M., 1965: The Temperature Regime of Soils. Sivan Press, $218 \mathrm{pp}$.

Smagorinsky, J., S. Manabe, and J. L. Holloway Jr., 1965: Numerical results from a nine-level general circulation model of the atmosphere. Mon. Wea. Rev., 93, 727-798.

Strack, J. E., 2001: Sensitivity of model-generated daytime surface heat fluxes over snow to land-cover changes. M.S. thesis, Dept. of Atmospheric Science, Paper 703, Colorado State University, Fort Collins, CO, 65 pp.

Thomas, G., and P. R. Rowntree, 1992: The boreal forests and climate. Quart. J. Roy. Meteor. Soc., 118, 469-497. 
Viterbo, P., and A. K. Betts, 1999: Impact on ECMWF forecasts of changes to the albedo of the boreal forests in the presence of snow. J. Geophys. Res., 104, 27 803-27 810.

Vogelmann, J. E., T. L. Sohl, P. V. Campbell, and D. M. Shaw, 1998: Regional land cover characterization using Landsat thematic mapper data and ancillary data sources. Environ. Monit. Assess., 51, 415-428.

Walko, R. L., and Coauthors, 2000: Coupled atmosphere-biophysicshydrology models for environmental modeling. J. Appl. Meteor., 39, 931-944. 